TITLE:

\title{
Three-dimensional imaging of the plasma parameters of a moving cusp aurora
}

\author{
$\operatorname{AUTHOR}(\mathrm{S}):$ \\ Taguchi, Satoshi; Hosokawa, Keisuke; Ogawa, \\ Yasunobu
}

\section{CITATION:}

Taguchi, Satoshi ... [et al]. Three-dimensional imaging of the plasma parameters of a moving cusp aurora. Journal of Atmospheric and Solar-Terrestrial Physics 2015, 133: 98 110

ISSUE DATE:

2015-10

URL:

http://hdl.handle.net/2433/214277

\section{RIGHT:}

(C) 2015. This manuscript version is made available under the CC-BY-NC-ND 4.0 license http://creativecommons.org/licenses/by-nc-nd/4.0/; 許諾条件により本文ファイルは 2017-10-01に公開.; This is not the published version. Please cite only the published version.; この論文は出版社版でありません。引用の際には出版社版をご確認ご利用くだ さい。 


\section{Three-dimensional imaging of the plasma parameters of a moving cusp aurora}

Satoshi Taguchi, ${ }^{1,2,3}$ Keisuke Hosokawa, ${ }^{1,2}$ and Yasunobu Ogawa ${ }^{4,5}$

${ }^{1}$ Department of Communication Engineering and Informatics, University of

Electro-Communications, Tokyo 182-8585, Japan

${ }^{2}$ Center for Space Science and Radio Engineering, University of Electro-Communications,

Tokyo 182-8585, Japan

${ }^{3}$ Now at Department of Geophysics, Kyoto University, Kyoto 606-8502, Japan

${ }^{4}$ National Institute of Polar Research, Tokyo 190-8518, Japan

${ }^{5}$ Department of Polar Science, SOKENDAI (Graduate University for Advanced Studies), Kanagawa 240-0193, Japan

Corresponding author: S. Taguchi, Department of Geophysics, Kyoto University, Kyoto, 606-8502, Japan (taguchi@kugi.kyoto-u.ac.jp tel:+81-75-753-3951)

\section{Highlights:}

- 3D images of plasma parameters in a moving aurora from IS radar and all-sky imager

- Spatial relations are found between the cusp aurora, elevated $\mathrm{Ti}$, and enhanced $\mathrm{Ne}$

- The relationships are explained by the presence of a moving twin-convection cell

\section{Keywords:}

Cusp aurora; ion temperature; electron density; three-dimensional images;

Submitted to Journal of Atmospheric and Solar-Terrestrial Physics 


\section{Abstract}

During a period of negative IMF $B_{Z}$ on 13 January 2013, an all-sky imager at Longyearbyen, Svalbard observed a mesoscale aurora moving towards the east-northeast in the cusp, passing through the field of view of the EISCAT Svalbard Radar (ESR) elevation scan. The elevation scans that were being performed at that time have a horizontal coverage of approximately $300 \mathrm{~km}$, at an altitude of $300 \mathrm{~km}$. The plasma data obtained from the elevation scans and the 630-nm aurora emission data from the all-sky imager have shown that ion temperature enhanced $50-60 \mathrm{~s}$ earlier than electron density, and that the maximum auroral intensity in the ESR's field of view occurred about $40 \mathrm{~s}$ after the electron density enhancement. On the basis of these results we have constructed three-dimensional images of elevated ion temperatures and enhanced electron density associated with the mesoscale moving cusp aurora. The three-dimensional image shows that the enhancement of the ion temperature is prominent in the horizontal area of $\sim 160 \mathrm{~km} \times \sim 80 \mathrm{~km}$ below an altitude of $\sim 300 \mathrm{~km}$, and that this volume forms on the forward side of the enhanced electron density region. We interpret these configurations as being a result of a mesoscale twin-cell convection, which is embedded in the background flow such that the symmetrical axis of the twin-cell is inclined from the background flow direction by several tens of degrees. Our method for visualizing three-dimensional features such as these could be an effective approach to understanding the mesoscale dynamics of the cusp, which is usually located in latitudes that are difficult for the currently-operated radars that permit three-dimensional, simultaneous measurements to investigate. 


\section{Introduction}

A poleward moving auroral structure is a typical phenomenon of the dayside cusp of the high-latitude ionosphere, and is commonly detected by ground-based optics, except for when interplanetary magnetic field (IMF) is strongly northward (e.g., Sandholt et al., 1986; Lockwood et al., 1989; Fasel et al., 1995; Sandholt and Farrugia, 2003; Okasvik et al., 2004, Taguchi et al., 2012). As has been shown by many researchers, the auroral form moves in a direction that is consistent with the motion of the magnetic field line after reconnection on the dayside magnetopause, and it is now widely accepted as being the ionospheric signature of the magnetic flux motion driven by intermittent reconnection, known as a flux transfer event (FTE) (Haerendel et al., 1978; Russell and Elphic, 1978).

In addition to the motion of the entire structure, the auroral form often includes a region of flow enhancement. Using data obtained from the EISCAT radar and data from a meridian scanning photometer, Lockwood et al. (1989) showed that the flow in the cusp is enhanced concurrently with dayside auroral transients. Milan et al. (1999) performed simultaneous observations of periodic auroras and flows in the cusp using a meridian-scanning photometer and HF radar; they showed that some dayside auroral transients are accompanied by flow enhancement.

Oksavik et al. (2004) presented evidence for the relationship between a moving auroral form and a two-dimensional flow pattern, from the EISCAT Svalbard Radar (ESR) and an all 
sky imager. They examined the locations of the flow enhancements relative to the moving auroral structure, and found the auroral form to be located in a cell of a twin-vortex flow pattern, as predicted by Southwood $(1985 ; 1987)$, although the return flow in the high-latitude part of a twin-vortex does not occur in the early stages of the moving aurora (Taguchi et al., 2010).

Lockwood et al. (1993) examined aurora intensity from a meridian-scanning photometer and ion temperature from the mainland EISCAT radar, and showed that the latitudinal profiles of the ion temperature is similar to that of the aurora $(630 \mathrm{~nm})$ intensity. Moen et al. (2004a) presented a 4-hour cusp observation event, and indicated that most of brief enhancements in ion temperature occur almost concurrently with the poleward-moving aurora events. From a multi-instrumental study, including an auroral imager onboard a spacecraft (Mende et al., 2000), Taguchi et al. (2009) have shown that the mesoscale region of elevated ion temperature moves azimuthally in the cusp following brightening of the proton aurora.

Elevated ion temperature can also be seen as a persistent, latitudinal band in the cusp. Using mainland EISCAT data, Davies et al. (2002) have shown that a band of elevated ion temperature exists in the typical cusp latitudes. Moen et al. (2004b) also used the EISCAT radar, and reported an event in which a band of high ion temperature moved back and forth several times across the radar's field of view in a north-south direction.

Regardless of whether a phenomenon in the cusp is intermittent or persistent, the collocation of elevated ion temperatures and flow enhancements can be explained by the 
following relationship, based on frictional interactions associated with relative ion-neutral drift (e.g., St.-Maurice and Hanson, 1982):

$$
T_{\mathrm{i}}=T_{\mathrm{n}}+\left(m_{\mathrm{n}} / 3 k_{\mathrm{B}}\right)\left|\boldsymbol{v}_{\mathrm{i}}-\boldsymbol{v}_{\mathrm{n}}\right|^{2}
$$

where $T_{\mathrm{i}}$ and $T_{\mathrm{n}}$ are the ion and neutral temperatures, respectively, $k_{\mathrm{B}}$ is the Boltzmann constant, $\boldsymbol{v}_{\mathrm{i}}$ and $\boldsymbol{v}_{\mathrm{n}}$ are the ion and neutral drift velocity perpendicular to the Earth's magnetic field, respectively, and $m_{\mathrm{n}}$ is the collision-frequency-weighted average neutral mass. Equation (1) is derived from the ion energy equation (Banks and Kockarts, 1973), and its simplification to equation (1) is based on several assumptions, including the steady state assumption. These assumptions have been shown to be reasonable for usual $F$-region phenomena by St.-Maurice and Hanson (1982).

Elevated ion temperature in the cusp is also very important, as it may be a cause of ion upflow. From observations made in the nightside auroral oval, Wahlund et al. (1992) have shown that there is a category of ion outflow that can be related to enhanced ion temperature. Moen et al. (2004a) have shown that this is also true in the cusp. Additionally, Ogawa et al. (2009) statistically analyzed data from the ESR, and showed that more than $70 \%$ of ion upflow events identified between 1000 and 1500 Magnetic Local Time (MLT) are related to either ion temperature increase or electron temperature increase.

The purpose of the present paper is to identify three-dimensional structure of elevated ion temperature and its spatial relation to the enhanced electron density region in a moving 
auroral form in the cusp. Currently, even two-dimensional horizontal imaging is very limited.

Carlson et al. (2002) presented a two-dimensional horizontal image of elevated ion temperature, and provided evidence of its general collocation with an electron density enhancement, in the form of a polar patch, using data obtained by the ESR antenna azimuth scan. Ideally, definitive data for three-dimensional images should come from a radar that permits three-dimensional, simultaneous measurements of ionospheric parameters. However, such observations are possible only in two locations: Poker Flat in Alaska, and Resolute Bay in Canada. The Advanced Modular Incoherent Scatter Radar located at Poker Flat $\left(\sim 65.4^{\circ}\right.$ geomagnetic latitude) have provided three-dimensional images of various phenomena in the nightside auroral oval, which generally occur at geomagnetic latitudes (MLAT) of less than $70^{\circ}$ (see Kelly and Heinselman, 2009 and reference therein). In contrast, a similar radar at Resolute Bay, which is located at much higher latitudes of $\sim 82.8^{\circ}$ MLAT, is suitable for studying polar cap phenomena (e.g., Bahcivan et al., 2010).

The cusp is typically located in latitudes that neither of these radars can observe. The dayside cusp shifts to a lower latitude as the negative component of IMF $B_{Z}$ becomes larger, however, the cusp would still be in latitudes that the radar at Polar Flat cannot observe substantially, even if IMF $B_{\mathrm{Z}}$ drops to $-10 \mathrm{nT}$, according to the empirical relationship between cusp latitude and IMF $B_{\mathrm{Z}}$ (Newell et al., 1989; Frey et al., 2003). Moving cusp auroral forms separate from the poleward boundary of the persistent cusp, and often move up to several degrees of latitude. These auroral forms usually fade out before reaching $80^{\circ}$ MLAT however (e.g., Oksavik et al., 2004; Taguchi et al., 2012), and so do not enter the field 
of view of the radar at Resolute Bay.

In this study we construct a three-dimensional image of the elevated ion temperature and enhanced electron density associated with a moving cusp aurora, based on coordinated observations from the ESR at Longyearbyen $\left(\sim 75.4^{\circ}\right.$ MLAT) in Svalbard, Norway, and an all-sky imager in the Kjell Henriksen Observatory (http://kho.unis.no/) located nearby. Elevation scans made with the steerable $32 \mathrm{~m}$ dish antenna of the ESR can produce two-dimensional (altitude - ground distance from the radar) profiles. To make a three-dimensional image, we combine these two-dimensional profiles in such a way that takes into account the spatial relationships between the radar's field of view and the moving cusp aurora.

\section{ESR Elevation Scan and All-Sky Imager}

Elevation scans were performed at angles of $30^{\circ}-60^{\circ}$ toward the northwest during $07-11$ UT on 13 January 2013. Each scan has a sweep time of $48 \mathrm{~s}$, and data were recorded every $3.2 \mathrm{~s}$. The height resolution is $\sim 16 \mathrm{~km}$ at an altitude of around $200 \mathrm{~km}$ and $\sim 28 \mathrm{~km}$ at an altitude of around $500 \mathrm{~km}$. The elevation scans have a horizontal coverage of approximately $300 \mathrm{~km}$ at an altitude of $300 \mathrm{~km}$. The average scan speed at this altitude is $6.25 \mathrm{~km} \mathrm{~s}^{-1}$. We will take variations observed with this fast scan as a spatial variation. One moving auroral form passed through the ESR's field of view at around 0935 UT. The horizontal extent of the moving aurora and its motion as an entire structure are important for this study, and these parameters are obtained from an all-sky imager. 
Our all-sky imager was installed and routine data collection begun at the end of October 2011 (Taguchi et al., 2012). The imager uses an electron multiplier charge-coupled device camera (Hamamatsu, C9100-13) with an imaging resolution of $512 \times 512$ pixels. As has been shown by Taguchi et al. (2012), the $630.0 \mathrm{~nm}$ red line data from this camera can provide detailed information on the extent of moving auroral forms in the cusp. The high sensitivity of this camera is also very effective in identifying the structure of polar cap patches (Hosokawa et al., 2013a, b).

In the first observation season, from the end of October 2011 to the end of February 2012, the $630.0 \mathrm{~nm}$ data were obtained with an exposure time of $4 \mathrm{~s}$ (Taguchi et al., 2012; Hosokawa et al., 2013a, b). For the second year of observation, which includes the present event, we modified the observation mode slightly so that $630.0 \mathrm{~nm}$ images can be obtained with an exposure time of $1 \mathrm{~s}$, as well as $4 \mathrm{~s}$. In the present study, we used data obtained with an exposure time of $1 \mathrm{~s}$. As is shown later, images with this short exposure time are more helpful in identifying the location of the maximum intensity in the auroral form, even though the data were not obtained at regular intervals because of the constraints of the software controlling the automated observation system.

\section{Observations}

\subsection{Overview of the Event of 13 January 2013}

Figure 1 shows the $630.0 \mathrm{~nm}$ all-sky image taken at 0936:02 UT. The all-sky image is projected onto an Earth-centered sphere at a height of $300 \mathrm{~km}$, with a background of the 
geomagnetic coordinate system. A longitudinally elongated band of strong emission occurs across the whole field of view, and spanning 1000-1500 MLT. This means that the near-noon part of the dayside auroral oval is clearly seen. A mesoscale intensification is seen at $\sim 1210$ MLT in the poleward part of the $630 \mathrm{~nm}$ dayside auroral oval, indicated by the pink arrow. This is the auroral form that we focus upon in this study. As is shown later, this aurora moves towards the east-northeast.

In Figure 1 the white star symbol represents the location of Longyearbyen, where the ESR and the all-sky imager are situated. The line of sight from Longyearbyen to the observed moving auroral form takes a path approximately above the northern coastline of Greenland. This is toward northwest in geographical coordinates, and is the fixed azimuthal direction of our elevation scans of the ESR. The opposite southeastern direction is defined as the positive $X$-axis, as shown in Figure 1. The $Y$-axis is defined as geographically northeast. The dotted rectangle, which includes the auroral form of interest, is a region made from sides parallel to the $X$-axis and the $Y$-axis, and will be used in Figure 2.

Figure 2 shows an example of the spatial relationships between the ESR's field of view and the auroral form. This aurora image has the same original data as the image in Figure 1, but is displayed in a Cartesian coordinate system. The horizontal axis of the coordinate system ( $X$-axis, positive to the right) is geographically southeast, as mentioned above. The $Y$-axis is toward the northeast. The inset of Figure 2 shows a schematic illustration of the configuration in the $Y=0$ plane. We set the origin as the point where the ESR beam, having an elevation angle of $60^{\circ}$, intersects with $300 \mathrm{~km}$ altitude. The $X-Y$ plane is thus a tangential 
plane of a spherical surface at $300 \mathrm{~km}$ altitude. The $Z$-axis, which is not shown here, completes a right-handed system. The line segment shown by the gray bar at $Y=0$ (both in the main panel and the inset) represents the range over which the ESR beam intersects this plane. One sweep from $30^{\circ}$ to $60^{\circ}$ (or $60^{\circ}$ to $30^{\circ}$ ) takes $48 \mathrm{~s}$. The center of the aurora occurs at an elevation angle of roughly $50^{\circ}$, i.e., at a zenith angle of $40^{\circ}$. It should be noted that for the aurora image shown in Figure 2, the original image was smoothed with a boxcar average with a window of $7 \times 7$ pixels to suppress noise. An area of $20 \mathrm{~km} \times 20 \mathrm{~km}$ on a spherical surface at an altitude of $300 \mathrm{~km}$ is projected to $7 \times 7$ pixels when it is observed at zenith angles of about $40^{\circ}$.

Figure 3 shows solar wind data (5 min OMNI data) during 0700-1100 UT on 13 January 2013. The OMNI data are time-shifted to the Earth's bow shock nose. Any time delay for the propagation from the bow shock nose to the polar ionosphere is not considered in the plot shown in Figure 3. The dotted line in Figure 3 indicates the time at which the aurora image shown in Figures 1 and 2 was captured, specifically 0936:02 UT. IMF $B_{Y}$ became negative at around 0820 UT (Figure 3b), well before the appearance of the aurora of interest, and then remained negative. IMF $B_{\mathrm{Z}}$ was weakly negative $(-1 \mathrm{nT}$ to $-3 \mathrm{nT})$ for the majority of the interval (Figure 3c). The IMF clock angle (Figure 3d), which is calculated from $B_{\mathrm{Y}}$ and $B_{\mathrm{Z}}$ (Figure $3 \mathrm{~b}$ and c) was about $240^{\circ}$ at the time shown with the dotted line. When $B_{\mathrm{Y}}$ is negative, eastward plasma flow is caused in the northern hemisphere cusp. As expected, the aurora was seen to move east-northeastward. Detailed description of the aurora motion is included in the next section. 
The $X$-component of the IMF, $B_{\mathrm{X}}$, was relatively constant during the studied interval (Figure 3a). Solar wind plasma parameters were also relatively stable (Figures 3e-g). The solar wind plasma density, $N_{\mathrm{sw}}$, was approximately $5 \mathrm{~cm}^{-3}$ throughout the studied interval (Figure 3e). The solar wind speed and dynamic pressure were approximately constant at 400 $\mathrm{km} \mathrm{s}^{-1}$ (Figure 3f) and $1.6 \mathrm{nPa}$ (Figure 3g), respectively.

\subsection{Motion of Auroral Form}

Figure 4 shows aurora images at three different times during the event. The image in Figure 4a was obtained at 0935:22 UT, $40 \mathrm{~s}$ before the image shown in Figure 2 was captured. The other two images (Figures $4 \mathrm{~b}$ and $\mathrm{c}$ ) are observations made after 0936:02 UT (Figure 2). Each image has the same format as the one in Figure 2, except for the inclusion of a black dot inside the image, which indicates the location of maximum intensity in each auroral form. We determined the maximum intensity of the auroral form after excluding strong emission regions (defined as more than $2.9 \mathrm{kR}$ ) extending continuously from the boundary of the roughly-quadrangular image.

In Figure 4a the $X$-axis, or the gray bar, skims the forward part of the auroral form, meaning that the auroral form has just begun to intersect the ESR's field of view. Figure 4b, captured at 0936:08 UT shows that the relatively strong aurora intensity (defined here as more than $2.5 \mathrm{kR}$ ) occurs between approximately $Y=\sim-60 \mathrm{~km}$ and $Y=\sim 40 \mathrm{~km}$, and that the $X$-axis passing through the middle part of the auroral form. It is evident from these two Figures that the aurora motion has a component towards positive $Y$. This kind of motion can 
also be recognized from the shift of the location of maximum intensity (black dots in Figures 4a and b) towards positive $Y$. In Figure $4 \mathrm{~b}$, we note that a part of the auroral form, between approximately $X=-80 \mathrm{~km}$ and $-160 \mathrm{~km}$ (indicated by the arrow), is located relatively deep in the positive $Y$ region, suggesting that this part crossed the radar's field of view first.

In Figure 4c, which was captured at 0936:49 UT, the $X$-axis passes through the trailing edge of the auroral form, meaning that most of the horizontal extent of the auroral form had already crossed the radar's field of view. The point of maximum intensity within the auroral form is now on the positive side of the $Y$-axis. An auroral form with stronger intensities appeared from the eastward side (i.e., $X>0$ and $Y>0$ in Figure 4c) just before this time, and is located adjacent to the auroral form of interest to this study. As mentioned above, most parts of these strong emissions were not used for the determination of the maximum intensity of the auroral form.

Our all-sky imager detected the initial appearance of the moving cusp aurora well on the westward side of the radar's field of view at 0935:02 UT (not shown). Figure 5 represents the motion of the aurora from this start time to the end time (0937:21 UT). Positions of the maximum intensity of the auroral form (i.e., the black dot in Figure 4) are shown throughout the lifetime of the auroral form. To eliminate misleading spikes in noise, we smoothed each image in the same way as for Figure 2, and then determined the position of the maximum intensity. All available data are plotted in Figure 5. As has been stated in Section 2, the data (1-s resolution) were not obtained at regular intervals.

It is clear from Figure 5 that the aurora moves generally in the direction of increasing $X$ 
and $Y$. The red line is an ordinary least squares linear regression fit for the points of maximum intensity for 0935:02-0936:49 UT. The equation for this line is $Y=114+1.48 X$ with units of kilometers. The point at 0936:22 UT deviates the most from this red line. We note, however, that the image at 0936:22 UT have a secondary peak at a point that is very close to the red line (not shown). For all other points (up to 0936:49 UT), the deviation from the red line is less than $20 \mathrm{~km}$. As is shown later, we use a spatial bin of $20 \times 20 \mathrm{~km}$ for the construction of a three-dimensional image. For that purpose, we can regard the red line as being indicative of the overall motion of the aurora.

As was mentioned earlier, the positive $X$ direction is toward geographically southeast, and the positive $Y$ direction is toward geographically northeast. The gradient of the red line indicates that the overall motion of the aurora is towards the geographically east-northeast, which is roughly eastward in the geomagnetic coordinate around Svalbard. The length along this red line represents a distance of approximately $89.4 \mathrm{~km}$; the average speed of the aurora during the movement period of $107 \mathrm{~s}$ is therefore estimated to be $\sim 0.84 \mathrm{~km} \mathrm{~s}^{-1}$. This red line passes through the position at 0936:08 UT. This time will be taken as the reference time for the production of three-dimensional images of the plasma parameter. We also took another approach for the determination of the overall motion of the aurora, and obtained a similar result. This will be discussed in Section 5.4.

In Figure 5 the dashed lines indicate the behavior of the aurora in its final stage. We did not use these three positions, shown by the triangles, on the dashed lines for estimating the speed of aurora motion. During this period the moving aurora of interest was located adjacent 
to a newly formed aurora, visible in the image taken at 0936:49 UT (Figure 4c), and it is difficult to determine whether the measured maximum intensity actually belongs to the original moving aurora.

\subsection{Variations in ESR Parameters and Auroral Intensity}

The ESR elevation scan data for 0932:00-0940:00 UT are plotted in Figure 6. Four parameters: electron density $\left(N_{\mathrm{e}}\right)$, electron temperature $\left(T_{\mathrm{e}}\right)$, ion temperature $\left(T_{\mathrm{i}}\right)$, and line of sight ion velocity $\left(V_{\mathrm{i}}\right)$, are shown as UT versus altitude, together with the variation in elevation angle (bottom, Figure 6e). The four plotted parameters are 12.8-s integration of the data. As is shown later, these data are used for the construction of a three-dimensional image, although data with much high time resolution (3.2 s) have also been shown to be useful for producing a two-dimensional image (Carlson et al., 2002). The two black triangles, shown immediately above Figure 6a, indicate the $1 \mathrm{~min} 47 \mathrm{~s}$ interval during which the moving aurora of interest was observed (see Figure 5). The red triangle is $110 \mathrm{~s}$ earlier than that shown by the left-most black triangle, and represents a possible earliest time for the initiation of phenomena related to the moving cusp aurora, because the theoretical lifetime of the $\mathrm{O}\left({ }^{1} D\right)$ state of atomic oxygen is $110 \mathrm{~s}$ (e.g., Rees, 1989). We therefore focused on ESR data obtained after the time shown by the red triangle.

Figure 6e shows the variation in elevation angle, with points plotted every $3.2 \mathrm{~s}$. The four red lines labeled $A, B, C$, and $D$ in Figure 6e indicate intervals when the elevation angle is between $40^{\circ}$ and $50^{\circ}$. This angle range covers the region from $(X, Y)=(-80,0) \mathrm{km}$ to $(-160$, 
$0) \mathrm{km}$ at $Z=300 \mathrm{~km}$. As mentioned above in Figure $4 \mathrm{~b}$, this is the segment in which the radar's field of view detected the traveling front of the aurora.

Seven 12.8 -s intervals that overlap with the four periods $A, B, C$, and $D$, are shown as boxes labeled 1 to 7 in Figure $6 \mathrm{a}\left(N_{\mathrm{e}}\right)$ and $\mathrm{c}\left(T_{\mathrm{i}}\right)$. The box labeled 7 is $25.6 \mathrm{~s}$ after time 6 , and this time difference is shorter than the difference between time 4 and time 5 (or time 2 - time 3). This is simply because the 12.8-s interval at time 7 overlaps with the beginning of the period $D$. We did not include the interval immediately after time 7 , because we regarded the data at this time as representing phenomena that did not belong to the aurora of interest. The reason for this will be described below. The box labeled 0 shown in these panels will be used later.

The $V_{\mathrm{i}}$ data in Figure $6 \mathrm{~d}$ show a quasi-periodic pattern in which the region with velocities towards the radar, shown by a greenish/bluish color, appears to be invaded from lower altitudes by a region with velocities directed away from the radar, shown by a reddish color, as the elevation angle increases. This suggests that a flow boundary exists in the $F$-region over a broad range of altitude, i.e., extending from low altitude to high altitude, presumably along the near-vertical magnetic field lines. The radar's beam would pass through such a boundary at higher altitudes when the elevation angle is higher. As is shown later, the region with velocities toward the radar (greenish/bluish color in Figure 6d), occurring on the poleward side of the possible flow boundary, forms the main part of the east-northeastward moving aurora.

Figures 7a, 7b, and 7c show the expanded plots of the ESR $N_{\mathrm{e}}, T_{\mathrm{i}}$, and elevation angle 
for 0933:00 - 0937:00 UT, respectively. The boxes labeled 1 to 7 also show the same 12.8-s intervals as those shown in Figure 6. $N_{\mathrm{e}}$ at an altitude of around $300 \mathrm{~km}$ increased sharply at time 5. At an altitude of around $250 \mathrm{~km}, N_{\mathrm{e}}$ increased sharply at time 6 . Before that time, i.e., at times $1-4$ no substantial enhancements occurred. An enhancement immediately after time 2 is outside the elevation angle range between $40^{\circ}$ and $50^{\circ}$ (Figure $7 \mathrm{c}$ ). We note that the aurora image data obtained around time 2 (not shown) suggest that this density enhancement, which occurred in the large elevation angles, is not related to the aurora structure of our interest. From Figure 7b, it appears that $T_{\mathrm{i}}$ enhancements at the altitudes of $250 \mathrm{~km}-300 \mathrm{~km}$ occurred before the $N_{\mathrm{e}}$ enhancements start. More detailed variations in $N_{\mathrm{e}}$ and $T_{\mathrm{i}}$ are shown below (Figure 8).

Figure $8 \mathrm{a}$ shows the variations in $N_{\mathrm{e}}$ (blue) and $T_{\mathrm{i}}$ (red), obtained at altitudes of $\sim 300 \mathrm{~km}$ and $\sim 260 \mathrm{~km}$ during the intervals labeled 0 to 7 . The horizontal axis represents the time in seconds from 0932:32 UT (i.e., $t=0$ ). At this starting time, the ESR beam has an elevation angle of $60^{\circ}$ (see Figure 6e). The error bars represent the standard deviation. $N_{\mathrm{e}}$ (blue) at an altitude of $300 \mathrm{~km}$ (also $260 \mathrm{~km}$ ) increased at time 2, and reached its maximum, $\sim 10^{11.4} \mathrm{~m}^{-3}$, at time $6(t=179.2 \mathrm{~s})$. Then, $N_{\mathrm{e}}$ at these altitudes decreased at time 7 , although its decrease at an altitude of $260 \mathrm{~km}$ is modest. The error bar on each $N_{\mathrm{e}}$ measurement is very small when compared to the above-mentioned increase/decrease in the averaged $N_{\mathrm{e}}$. For $T_{\mathrm{i}}(\mathrm{red})$, the average at an altitude of $260 \mathrm{~km}$ was relatively high at times 3 and 4 . The average at an altitude of $300 \mathrm{~km}$ reached a maximum at time 3 . Although the error bar at this time is relatively large, the $T_{\mathrm{i}}$ range determined by that error bar is still much higher than those at 
times $0,4,5,6$, and 7 . It is evident that $T_{\mathrm{i}}$ reached its maximum at earlier times than $N_{\mathrm{e}}$. The time difference between the $N_{\mathrm{e}}$ maximum and $T_{\mathrm{i}}$ maximum is $50-60 \mathrm{~s}$. We note that it is not surprising that $T_{\mathrm{i}}$ at an altitude of $260 \mathrm{~km}$ has a maximum at time 4 , and that $T_{\mathrm{i}}$ at an altitude $300 \mathrm{~km}$ has a relatively low value. The effect of the frictional heating on the $T_{\mathrm{i}}$ profile decreases with altitude, and its negative gradient can be large between altitudes of $200 \mathrm{~km}$ and $300 \mathrm{~km}$, as was shown by Schunk and Sojka (1982).

Figure $8 \mathrm{~b}$ shows the temporal variations in auroral intensity as it passed through three points $(X, Y)=(-80,0),(-120,0)$, and $(-160,0) \mathrm{km}$ in the aurora mapped to $Z=300 \mathrm{~km}$. The range from $(X, Y)=(-160,0)$ to $(-80,0) \mathrm{km}$ at $Z=300 \mathrm{~km}$ roughly represents the ESR elevation angles of $40^{\circ}-50^{\circ}$, where plasma data shown in Figure $8 \mathrm{a}$ are obtained. The auroral intensities at $X=-120 \mathrm{~km}$ and $-160 \mathrm{~km}$ show a clear peak at $t=216 \mathrm{~s}$ (indicated by a vertical line). The intensity at $X=80 \mathrm{~km}$ is also relatively high at this time, and reaches a maximum just $14 \mathrm{~s}$ later.

The delay in auroral intensity peak $(t=216)$ from the $N_{\mathrm{e}}$ peak is therefore approximately $37 \mathrm{~s}(=216-179.2 \mathrm{~s})$. This delay will be later referred to as $\tau$, and used for producing a three-dimensional image. Since the last 'non-contaminated' aurora was observed at 0936:49 UT (Figure 5), the delay of $37 \mathrm{~s}$ implies that the $N_{\mathrm{e}}$ data after 0936:12 UT (=0936:49 UT37s) may reflect phenomena that are different from the aurora that we are focusing on. As a result, we choose not to use the ESR data obtained after time 7 in the present study.

\section{Three Dimensional Images}


The short time delay of the aurora intensity peak from the $N_{\mathrm{e}}$ peak implies that the $N_{\mathrm{e}}$ enhancement and the aurora intensification have a common source in this event. In fact, the $N_{\mathrm{e}}$ enhancement is collocated with high $T_{\mathrm{e}}$ at altitudes of $260 \mathrm{~km}-370 \mathrm{~km}$ (Figures 6a and 6b), and since the main source of high $T_{\mathrm{e}}$ at these altitudes is the electron precipitation, the electron precipitation would be responsible for the $N_{\mathrm{e}}$ enhancement. This suggests that the enhanced $N_{\mathrm{e}}$ region is moving in a similar manner to the auroral form. Moen et al. (2004a) have indicated that most of brief enhancements in ion temperature occur almost concurrently with the poleward-moving aurora events observed with a meridian-scanning photometer. It would be reasonable to assume that the elevated $T_{\mathrm{i}}$ region is also moving.

In addition, we assume that the spatial distributions of the enhanced $N_{\mathrm{e}}$ region and the elevated $T_{\mathrm{i}}$ region do not change over the course of a few minutes. The auroral form appears to be expanding gradually and somewhat diffusive during a few minutes (Figure 4), which implies that there should be some modest change in the $N_{\mathrm{e}}$ distribution. However, since auroral variations in the three different directions are very similar (Figure $8 \mathrm{~b}$ ), there would be no drastic change at the central part of the $N_{\mathrm{e}}$ distribution. For the ion temperature distribution, we do not have some grounds for its quasi-stability, but we will explain the main result obtained from that assumption later. We note that changes in $N_{\mathrm{e}}$ and $T_{\mathrm{i}}$ over the course of a few minutes (Figures 6, 7, and 8) do not exclude the possibility that the structure is quasi-stable. The structure is moving, and each radar scan looks into different parts of the moving structure.

Taking $\boldsymbol{V}=\left(V_{\mathrm{X}}, V_{\mathrm{Y}}\right)$ as the speed of their distributions, we can express the positions of the 
ESR beam in a coordinate system moving with $\boldsymbol{V}$ as follows:

$$
\begin{aligned}
& X=X_{\mathrm{ESR}}-V_{\mathrm{X}}\left(t-t_{0}-\tau\right) \\
& Y=V_{\mathrm{Y}}\left(t-t_{0}-\tau\right)
\end{aligned}
$$

where $X_{\mathrm{ESR}}$ is the position of the ESR elevation scan at a given $Z$ plane in an original coordinate system, and $t-t_{0}$ is the time difference from the reference time $\left(t_{0}\right)$. In this time difference we included a time delay $(\tau)$ of the variations in auroral intensity from those of $N_{\mathrm{e}}$. We note that equation (2) can be applied to any $Z$ plane, and that $Y_{\mathrm{ESR}}$ is not included in equation (2) because $Y_{\mathrm{ESR}}$ is zero in any $Z$ plane (see Figure 2).

Figure 9 shows the result from equation (2) for $\tau=37 \mathrm{~s}$, and $t_{0}=216 \mathrm{~s}$, (i.e., 0936:08 UT), at $Z=300 \mathrm{~km}$, alongside the auroral image at this time. $\left(V_{\mathrm{X}}, V_{\mathrm{Y}}\right)$ is approximated as a constant velocity of the average auroral motion in the $X$ and $Y$ directions, respectively (Figure 5), such that $0.84 \times(0.560,0.829)=(0.47,0.70) \mathrm{km} \mathrm{s}^{-1}$, where $(0.560,0.829)$ is the unit vector of the gradient (i.e., 1.48) of the equation obtained from Figure 5. For $t$, we used a 3.2-s time step starting at 0933:20 UT, as shown by the red triangle in Figure 6a.

For example, the start position $(X, Y)=(-202,144) \mathrm{km}$ in Figure 9 (first point in the top left), which corresponds to the observation at 0933:20 UT, is obtained using equation (2) in the following way. The time difference from the reference time, $t-t_{0}$ is $-168 \mathrm{~s}(=0933: 20$ UT-0936:08 UT). The ESR's beam passed through $X=-298 \mathrm{~km}$ at 0933:20 UT, therefore $X_{\mathrm{ESR}}=-298 \mathrm{~km}$. Using $V_{\mathrm{X}}=0.47 \mathrm{~km} \mathrm{~s}^{-1}, V_{\mathrm{Y}}=0.70 \mathrm{~km} \mathrm{~s}^{-1}$, and $\tau=37 \mathrm{~s}$, we find $(X, Y)=(-202$, 
144) $\mathrm{km}$.

The dark-gray arrows labeled 1 to 7 indicate the 12.8-s (4 times 3.2-s) intervals that have already been used in Figures $6 \mathrm{a}$ and $6 \mathrm{c}$. The dotted lines labeled $a 1$ and $a 2$ represent $12.8-\mathrm{s}$ intervals just before the observations at times 1 and 5, respectively. By adding data from these two intervals, we produced a rectangle-like imaging region in each $Z$ layer. We then used data from the nine intervals to make the three-dimensional images.

The thin dotted lines drawn parallel to the $X$ - and $Y$-axes represent a spatial bin of $20 \times 20$ $\mathrm{km}$. We also made 13 bins of $20 \mathrm{~km}$ for $Z=200 \mathrm{~km}$ to $440 \mathrm{~km}$. We input the 12.8 -s integrated $T_{\mathrm{i}}$ and $N_{\mathrm{e}}$ values from each of the nine intervals into these regular cubed bins, using equation (2). Since each interval covers three or four bins, as shown in Figure 9, those bins have the same $T_{\mathrm{i}}$ or $N_{\mathrm{e}}$ values.

Figure 10a shows a three-dimensional $N_{\mathrm{e}}$ image, constructed from the values in each bin with additional data interpolation. As was shown in Figure 9, this image includes the data obtained at times $1-7$ (Figures 6 and 7). A relatively large volume of enhanced $N_{\mathrm{e}}$ (reddish color) exists at $X>-80 \mathrm{~km}$, and its side surface at this location appears to be vertically aligned, thus almost aligned to the Earth's magnetic field (shown by the white downward arrows). This supports the idea that the enhancement is created by the precipitation of particles along the Earth's magnetic field. This enhanced $N_{\mathrm{e}}$ volume is present from approximately $Z=260$ $\mathrm{km}$ to $340 \mathrm{~km}$, which is around the altitude of the projected height of the $630-\mathrm{nm}$ auroral emission. The altitude profile may be clearer in $Y-Z$ plane plot, which will be shown later.

We did not include regions with very low density, defined here as $N_{\mathrm{e}}<3 \times 10^{10} \mathrm{~m}^{-3}$. 
Densities of such a low value are shown in a dark blue color in Figure 6a (or Figure 7a), therefore this exclusion does not affect the main part of the above three-dimensional image, which corresponds to the reddish or yellow colors in Figure 6a (or Figure 7a). For the data interpolation, we first took the minimum value $\left(\geq 3 \times 10^{10} \mathrm{~m}^{-3}\right)$ in each $Z$ layer. We then defined the outer boundary as a rectangular region in which any $X$ slice spanning the whole $Y$ range (from $Y=-100 \mathrm{~km}$ to $Y=300 \mathrm{~km}$ ) has two or more bins that contain actual observational values, and distributed the minimum value on the defined outer boundary for that layer. We performed a two-dimensional fit using a minimum curvature spline (Franke, 1982).

Figure $10 \mathrm{~b}$ shows the three-dimensional image of elevated $T_{\mathrm{i}}$. There exists a relatively large region between $X \sim-140 \mathrm{~km}$ and $X \sim 20 \mathrm{~km}$, labeled $A$, in which three higher temperature regions are seen to be aligned vertically. This dimension $(160 \mathrm{~km})$ is very similar to the dimension of the auroral structure in the $X$ direction (Figures 2 and 4). The top of Region $A$ is an altitude of $\sim 260 \mathrm{~km}$. At an altitude of around $300 \mathrm{~km}$, other high $T_{\mathrm{i}}$ regions, $B$ and $C$ exist. A further Region $D$ is located at an altitude of around $360 \mathrm{~km}$. These are also recognized in the $Y-Z$ profiles, which are shown below. We note, however, that only one ESR data point having $T_{\mathrm{i}} \geq 2500 \mathrm{~K}$ is included in small Region $C$ or Region $D$.

In Figures $11 \mathrm{a}$ and $11 \mathrm{~b}$ we show $Y-Z$ profiles of $N_{\mathrm{e}}$ and $T_{\mathrm{i}}$, respectively. In these plots transparent isocontours are shown in the same manner as the plots in Figure 10. The white dot in each Figure represents the origin that was defined in Figure 2. Figure 10a shows that the enhanced $N_{\mathrm{e}}$ region is located roughly around $Y=40 \mathrm{~km}$. The relatively strong aurora intensity occurs between approximately $Y=\sim 40 \mathrm{~km}$ and $Y=\sim-60 \mathrm{~km}$ at the reference time 
(Figure 4b). In other words, our approach is able to visualize the fact that the auroral form is extended behind a moving region of enhanced $N_{\mathrm{e}}$, which is created by electron precipitation.

Figure $11 \mathrm{~b}$ shows that the dimension of Region $A$ and $B$ in the $Y$ direction is roughly 80 km. Figure $11 \mathrm{~b}$ also shows that Region $B$ extends beyond Region $A$. Both regions appear to connect at $Y \sim 120 \mathrm{~km}$. We refer to Region $B$ on the more (or less) positive $Y$ side of $Y=100$ $\mathrm{km}$ as Region $B_{1}$ (or Region $B_{2}$ ). When Figure $11 \mathrm{a}$ and $11 \mathrm{~b}$ are compared, it is clear that most of the low-altitude heated volumes, Region $A$ and Region $B_{1}$ occur on the more positive $Y$ side of the enhanced $N_{\mathrm{e}}$ volume. The center of Region $A$ is at approximately $Y=80 \mathrm{~km}$, around $40 \mathrm{~km}$ away from the center of the enhanced $N_{\mathrm{e}}$ volume. At higher altitudes, Region $B_{2}$, Regions $C$ and $D$ overlap with the enhanced $N_{\mathrm{e}}$ region.

\section{Discussion}

\subsection{Heated Volume}

We have shown, for the first time, how elevated $T_{\mathrm{i}}$ is formed in three-dimensions associated with the moving cusp aurora. Since the ion temperature is enhanced by frictional heating, as shown in equation (1), the ions should be convecting at relatively high speed in the elevated $T_{\mathrm{i}}$ region. We have shown in Figures $10 \mathrm{~b}$ and $11 \mathrm{~b}$ that a 'heated volume' (Region $A$ ) is present below an altitude of $260 \mathrm{~km}$. This volume results mostly from the $T_{\mathrm{i}}$ data obtained at times 3 and 4 (Figure $6 \mathrm{c}$ or Figure $7 \mathrm{~b}$ ). We then examined the corresponding line of sight ion velocities, $V_{\mathrm{LOS}}$, at times 3 and 4 (Figure 6d). As expected, $V_{\mathrm{LOS}}$ has large negative values at those altitudes at times 3 and 4. 
To check if the electron gas does not act as a significant heat source for the formation of the ion heated volume, we show in Figure 12 how $T_{\mathrm{i}}$ exceeds $T_{\mathrm{e}}$ within the heated volume, which is defined as the reddish colored region $\left(T_{\mathrm{i}} \geq 2500 \mathrm{~K}\right)$ in the $3 \mathrm{D} T_{\mathrm{i}}$ plots. The horizontal axis of Figure 12 represents the altitude of the heated volume. For this, we used only those values from the bins that contain actual ESR observation data, without including the interpolated values. Although there is a weak trend of $T_{\mathrm{i}}$ approaching $T_{\mathrm{e}}$ as the altitude increases, $T_{\mathrm{i}}$ is evidently higher than $T_{\mathrm{e}}$ at almost all points. This indicates that the electron gas does not act as a significant heat source for the formation of the ion heated volume, in any of the identified regions (Figure 10b), and that some reason for the formation of the higher-altitude heated volume need to be considered. We note that the shape of our three-dimensional $T_{\mathrm{i}}$ images is not determined only with these data points (for $T_{\mathrm{i}} \geq 2500 \mathrm{~K}$ ) but also with more data points in the surrounding area having lower $T_{\mathrm{i}}$.

A possible reason for the formation of the higher-altitude heated volume, comprising Region $B_{2}$, Region $C$, and Region $D$, may be the upward heat flow caused by relative motion of the ions compared to the neutrals. The heat flow vector along the Earth's magnetic field direction, which is neglected in equation (1), includes a term proportional to the relative velocity of the ions against the neutrals (Conrad and Schunk, 1979). Upward ion flow would be enhanced in those enhanced $N_{\mathrm{e}}$ regions because soft electrons with relatively high energy fluxes precipitate there (Ogawa et al., 2003). For understanding how the upward heat flow produces inhomogeneous high $T_{\mathrm{i}}$ regions, which are seen as Region $B_{2}$, Region $C$, and Region $D$, further studies are needed. 
We note again that our three-dimensional images of $N_{\mathrm{e}}$ and $T_{\mathrm{i}}$ have been obtained on the basis of the assumptions that their spatial distributions do not change over the course of a few minutes. In reality, as has been shown in Figure 4, the auroral form appears to be expanding gradually and somewhat diffusive during a few minutes. This must cause some related change in the $N_{\mathrm{e}}$ distribution, and our three-dimensional images may be somewhat different from the actual snapshot at a specific time. A similar difference may be caused if the actual distributions of $N_{\mathrm{e}}$ and $T_{\mathrm{i}}$ include variations whose timescales are much shorter than a few minutes. We also assumed that the horizontal speed of their distributions is constant. This assumption is not a specific requirement for our main result. Slight variations in speed would not affect our main result, i.e., the heated volume's being on the forward side of the enhanced electron density volume.

\subsection{Spatial Relationship Between Elevated $T_{i}$ and Enhanced $N_{e}$ Volumes}

We now consider why the lower-altitude elevated $T_{\mathrm{i}}$ volume in Region $A$ and Region $B_{1}$ occurs on the forward side of the enhanced $N_{\mathrm{e}}$ volume. As mentioned in Section 4, the electron precipitation would be responsible for the $N_{\mathrm{e}}$ enhancement for the present event, suggesting that upward field-aligned currents should penetrate that region. Such collocation of a mesoscale upward field-aligned current and a cusp electron precipitation burst has been clearly observed, for example, in an event recorded by the DE 2 spacecraft, shown in Plate 1 (0251:32-0251:40 UT) in Taguchi et al (1993). We note from their Plate 1 that ion precipitation with higher energy and higher energy fluxes occurs both in the upward 
field-aligned current and in the adjacent downward field-aligned current (0251:15-0251:32

UT), representing a pair of field-aligned currents.

We consider a situation in which a pair of field-aligned currents exists in a region a few hundred kilometers across, as is seen in Plate 1 of Taguchi et al. (1993) to interpret the main point of our results, which indicates that the lower-altitude elevated $T_{\mathrm{i}}$ volume occurs on the forward side of the enhanced $N_{\mathrm{e}}$ volume. Each field-aligned current in the horizontal plane is assumed to be a semicircle of radius $150 \mathrm{~km}$, which is close to that of a moving mesoscale plasma precipitation (Taguchi et al., 2009). When we also assume that this pair current is closed by the field-perpendicular ionospheric current, and that Pedersen conductance, $\Sigma_{\mathrm{P}}$, which controls that field-perpendicular ionospheric current, is uniform for simplicity, we obtain:

$$
\nabla^{2} \phi=-j_{/ /} / \Sigma_{\mathrm{P}}
$$

where $\phi$ denotes the electric potential, determining plasma flow distributions, and $j_{/ /}$is the field-aligned current density (positive for downward current and negative for upward current). This pair current would be the ionospheric signature of an FTE (Southwood, 1985; 1987). As is shown below, we also introduce the background potential distribution to represent the overall motion of this current system, which is consistent with convection driven by reconnection at the magnetopause.

Figure 13 shows a numerical solution to equation (3) in a square $600 \mathrm{~km}$ wide. For the 
parameter on the right-hand side of equation (3), we took $j_{/ /} / \Sigma_{\mathrm{P}}$ to be $\pm 1.5 \times 10^{-6} \mathrm{Am}^{-2} \mathrm{~S}^{-1}$. The choice of this value is based on the average density of a typical cusp field-aligned current, $j_{/ /}=2 \times 10^{-6} \mathrm{Am}^{-2}$ (e.g., Sugiura et al., 1982), and on the Pedersen conductance just behind the terminator, $\Sigma_{\mathrm{P}}=1-2 \mathrm{~S}$ (Ishii et al., 1992, their Figure 8). This low conductance would be a result of scattering of the sunlight across the terminator. The hatched semicircle of Figure 13 represents the upward field-aligned current. We tilted the boundary between the upward and downward field-aligned currents by $45^{\circ}$ from the vertical $y$-axis axis. This tilt is introduced for interpreting the result obtained in Figure 8, as is shown later. The point is that the boundary tilts by several tens of degrees, not exactly, $45^{\circ}$. The $y$-axis represents the average direction of the auroral form, i.e., the direction of the red line in Figure 5, which means that the $x-y$ coordinate in Figure 13 is defined as $-34^{\circ}$ rotation of the $X$ - $Y$ coordinate shown in Figure 5. The electron density enhancement is not directly considered in this calculation, but must be collocated with the region of upward field-aligned current (hatched semicircle).

In Figure 13 the potential distribution $\phi$ is shown with the flow vector $\boldsymbol{v}_{\mathrm{i}}$ after the following transformation:

$$
\boldsymbol{v}_{\mathrm{i}}=-\nabla \phi \times \boldsymbol{B} /|\boldsymbol{B}|^{2}
$$

where $\boldsymbol{B}$ is the Earth's magnetic field vector, which is assumed to be directed into the plane in Figure 13, with a magnitude of 50,000 nT. We superimposed a background potential that is consistent with the motion of the aurora. We determined the background drift to be $0.8 \mathrm{~km} \mathrm{~s}^{-1}$ 
at $x=0$ on the basis of the result obtained in Figure 5 . The background flow, which is towards east-northeast, is driven by dayside reconnection for IMF $B_{\mathrm{Y}}$ negative, and should occur in a latitudinally limited region. We then assumed that the background flow is zero at $x=-300 \mathrm{~km}$. One of many possible electric field distributions satisfying these two conditions (i.e., $0.8 \mathrm{~km}$ $\mathrm{s}^{-1}$ at $x=0$ and zero at $x=300 \mathrm{~km}$ ) is:

$$
E_{0}=4(1+x / 300) \times 10^{-2}
$$

where $E_{0}$ and $x$ are units of $\mathrm{V} \mathrm{m}^{-1}$ and $\mathrm{km}$, respectively. The potential distribution is then

$$
\phi_{0}=-(1 / 15)(300+x)^{2} \times 10^{-3}
$$

where $\phi_{0}$ and $x$ are units of $\mathrm{kV}$ and $\mathrm{km}$, respectively. By inserting (6) into (3), we find that the assumed background potential represents the existence of a downward $j_{/ /}$and a $j_{/ /} \Sigma_{\mathrm{P}}$ of $4 / 3 \times 10^{-7} \mathrm{Am}^{-2} \mathrm{~S}^{-1}$. This downward field-aligned current is typical for the high-latitude part of the cusp in the present IMF situation, namely negative IMF $B_{\mathrm{Y}}$ (e.g., Taguchi et al., 1993). As was mentioned in Section 3.3, a flow boundary may be expected to exist near the twin field-aligned currents. We have assumed that the boundary lies outside $x=300 \mathrm{~km}$, and not considered the boundary in the numerical calculation.

Figure 13 shows that the flow is faster near the center, i.e., the boundary between the two semicircular field-aligned current regions, with a maximum flow of approximately 3.3 $\mathrm{km} \mathrm{s}^{-1}$. The overall flow pattern is not symmetric with respect to the boundary between the two field-aligned current regions. This asymmetry is not included in the twin-vortex flow pattern that was originally proposed by Southwood $(1985 ; 1987)$, but rather similar to the picture proposed by Taguchi et al. (2010) in that the return flow associated with downward 
field-aligned current is clearer than that with upward field-aligned current.

In Figure 13 the contours, which are overlapped in the high flow region, represent the $T_{\mathrm{i}}$ distribution $(\geq 2000 \mathrm{~K})$ calculated using the simplified version of equation $(1), T_{\mathrm{i}}=T_{\mathrm{n}}+$ $6.4 \times 10^{-4}\left|\boldsymbol{v}_{\mathrm{i}}-\boldsymbol{v}_{\mathrm{n}}\right|^{2}$, where an ambient gas is assumed to consist of atomic oxygen. For simplicity, we also assumed $T_{\mathrm{n}}$ and $\boldsymbol{v}_{\mathrm{n}}$ to be $500 \mathrm{~K}$ (e.g., St-Maurice and Hanson, 1984) and zero, respectively. High $T_{\mathrm{i}}$ appears near the center, and extends toward more positive $y$. This is because the fast flow region extends toward the more positive $y$ side of the downward field-aligned current region. The overall features of high $T_{\mathrm{i}}$, which indicate that the high $T_{\mathrm{i}}$ region extends in the moving direction of the auroral form, are similar to the existence of Region $A$ and Region $B_{1}$ in our three-dimensional modeling (Figure 11b). The twin cell model, which has been widely accepted for a moving cusp aurora, can explain the overall features by taking into account the background flow, although why Region $B_{1}$ is at somewhat higher altitudes than Region $A$ is not explained by this two-dimensional calculation.

The long black arrow in Figure 13 indicates the direction of the ESR's field of view $(-X$ direction). This direction is obtained by rotating $-x$ direction by $34^{\circ}$, as was mentioned in 5.2 . When the $45^{\circ}$-tilted structure moves with the background drift velocity, and passes through the ESR's field of view (the long black arrow in Figure 13), ESR would observe elevated $T_{\mathrm{i}}$ earlier than enhanced $N_{\mathrm{e}}$, which can explain the result shown in Figure 8 . The point is that the symmetrical axis of the structure tilts by several tens of degrees. If the symmetrical axis has no inclination, such that $x=0$, ESR would observe elevated $T_{\mathrm{i}}$ and enhanced $N_{\mathrm{e}}$ nearly simultaneously, which is inconsistent with the observation. 
We have shown, in Figure $11 \mathrm{a}$, that the enhanced $N_{\mathrm{e}}$ region is not symmetrical about $Y=40 \mathrm{~km}$. The lower altitude portion of the enhanced $N_{\mathrm{e}}$ volume appears to be depleted at more positive $Y$, from 60 to $100 \mathrm{~km}$, which is close to the center of Region $A$ heated volume. The $N_{\mathrm{e}}$ asymmetry seen in the lower altitude portion of the enhanced $N_{\mathrm{e}}$ volume might be explained by the increased $\mathrm{O}^{+}+\mathrm{N}_{2}$ reaction rate associated with frictional heating (Schunk et al., 1976).

\subsection{Comparison with Previous Observations}

We have shown in the three dimensional images of elevated $T_{\mathrm{i}}$ and enhanced $N_{\mathrm{e}}$ for a moving cusp aurora that the lower-altitude elevated $T_{\mathrm{i}}$ volume occurs on the forward side of the enhanced $N_{\mathrm{e}}$ volume, and that $630.0 \mathrm{~nm}$ auroral emissions occur on the backward side of the enhanced $N_{\mathrm{e}}$ region. Some events reported previously on the basis of the EISCAT radar are consistent with these features. Using mainland EISCAT data, Davies et al. (2002) presented an event in which a series of poleward-propagating $N_{\mathrm{e}}$ enhancements occurred in the prenoon cusp together with $T_{\mathrm{i}}$ enhancements. The authors showed that a clear region of elevated $T_{\mathrm{i}}$ proceeds in a poleward direction (just before 0900 UT in their Figures 4 and 6). This elevated $T_{\mathrm{i}}$ region appears to be located immediately poleward of the enhanced $N_{\mathrm{e}}$ region, although the authors did not mention this relation. Carlson et al. (2002) used ESR data, and presented a two-dimensional horizontal image of elevated $T_{\mathrm{i}}$ and enhanced $N_{\mathrm{e}}$. As the authors stated, their general collocation is clear. For the event shown in the upper panel of Figure 1 of their paper, however, the most elevated $T_{\mathrm{i}}$ region (top right of their Figure 1) 
appears to be located somewhat higher latitudes than the enhanced $N_{\mathrm{e}}$ region (top left). Moen et al. (2004a) compared the aurora emission data from a meridian-scanning photometer with the data from the $32 \mathrm{~m}$ antenna of the ESR pointing up along the magnetic field lines. In their Event $10 T_{\mathrm{i}}$ enhancement started earlier than the passage of the aurora structure at the ESR's field of view.

\subsection{Evaluation of the Velocity of the Auroral Form}

For the velocity in equation (2), we used a constant velocity of the average auroral motion mapped at an altitude of $300 \mathrm{~km}$ (Figure 5). The altitude of the $630.0 \mathrm{~nm}$ auroral emissions in the cusp may range from $200 \mathrm{~km}$ to $400 \mathrm{~km}$ or even higher. The upper part (i.e., altitude of $\sim 400 \mathrm{~km}$ ) of an aurora structure will appear at a shorter distance from the observation point, and the bottom part (i.e., altitude of $\sim 200 \mathrm{~km}$ ) will appear at a further distance. The boundary of the aurora of interest is clearer in a further distance than in a short distance (see Figure 4). As an alternative to the method used in Figure 5, we examined the distant boundary of the auroral form, where the bottom part (i.e., altitude of $\sim 200 \mathrm{~km}$ ) of the aurora structure may appear. For each auroral image during 0935:02 - 0936:49 UT (same as the interval shown in Figure 5), we searched for the most distant point that has an intensity of more than $2.5 \mathrm{kR}$ (yellow color in Figure 4) from the region of $-200 \mathrm{~km} \leq X \leq-100 \mathrm{~km}$ and $-100 \mathrm{~km} \leq Y \leq 100$ $\mathrm{km}$.

Figure 14 shows the positions of the obtained point and the comparison to the result obtained in Figure 5. The red line represents the regression line obtained in Figure 5. The 
magnitude of the average velocity, the unit vector of the velocity in the $(X, Y)$ coordinate, and the velocity in this coordinate, which were obtained in Figure 5, are shown here again. The black dots in the left part of Figure 13 represent the positions of the most distant point of the auroral form. These points show that the aurora moves generally in the direction of increasing $X$ and $Y$. The blue line is an ordinary least squares linear regression fit for these points. The equation for this blue line is $Y=307+2.05 X$ with units of kilometers. As is easily calculated from the unit vector for the gradient of the equation, the difference between the two gradients (red and blue) is only about $8^{\circ}$. This similarity supports that the velocity direction that we have used for the production of the three-dimensional image well represents the motion of the auroral structure.

The average velocity obtained from this regression line (blue color) is $\sim 1.2 \mathrm{~km} \mathrm{~s}^{-1}$. We used the similar method to the one used for the average velocity of $0.84 \mathrm{~km} \mathrm{~s}^{-1}$ in Figure 5 . In other words, both velocities have been estimated on the $X$-Y plane, i.e., a tangential plane of a spherical surface at an altitude of $300 \mathrm{~km}$. Actually, the length on that plane will be mapped to a shorter length at an altitude of $200 \mathrm{~km}$. In the present event the auroral form occurred at a zenith angle of about $40^{\circ}$. For this zenith angle, we can calculate that scale ratio to be 0.67 (Appendix A). Then, the velocity of the bottom part of the auroral structure is estimated to be $0.8(=1.2 \times 0.67) \mathrm{km} \mathrm{s}^{-1}$. This is very similar to the average velocity obtained in Figure 5, which supports that the magnitude of the velocity that we have used for the production of the three-dimensional image is reasonable.

\section{Conclusions}


Using 630-nm red line aurora data from the all-sky imager at Longyearbyen, Svalbard and plasma data from the ESR operated in a fast elevation scan mode, we have produced three-dimensional images of elevated $T_{\mathrm{i}}$ and enhanced $N_{\mathrm{e}}$ associated with a moving aurora in the cusp. The important results from the observations, which have been incorporated into the three-dimensional image processing, are that the ESR observation of elevated $T_{\mathrm{i}}$ occurred 50 - $60 \mathrm{~s}$ earlier than that of enhanced $N_{\mathrm{e}}$, and that the maximum auroral intensity in the ESR's field of view occurred about $40 \mathrm{~s}$ after the ESR-measured $N_{\mathrm{e}}$ enhancement.

The three-dimensional image we have constructed shows that the enhancement of the ion temperature is prominent in the horizontal area of $\sim 160 \mathrm{~km} \times \sim 80 \mathrm{~km}$ below an altitude of $\sim 300 \mathrm{~km}$, and that the heated volume occurs on the forward side of the enhanced electron density region. We have interpreted these configurations as being due to a mesoscale twin-cell convection, embedded in the background flow in such a manner that the symmetrical axis of the twin-cell is inclined from the background flow direction by several tens of degrees.

Ion drift is rapid around the symmetrical axis of the twin cell, and the ion temperature is enhanced by being frictionally heated there. Since the symmetrical axis of the twin-cell is inclined from the background flow direction, this heated volume lies on the forward side of the rear cell. This inclination is an important element in our interpretation. The rear cell would contain an upward field-aligned current in the present east-northeastward moving event. In this upward field-aligned current region electron densities would be enhanced, therefore an enhanced $N_{\mathrm{e}}$ volume would be formed on the rear side of the elevated $T_{\mathrm{i}}$ region. 
This geometry is also consistent with the higher-altitude $(>300 \mathrm{~km})$ feature, which shows that high ion temperature volumes tend to overlap with the region of enhanced $N_{\mathrm{e}}$ volume.

The method reported in this study has also allowed us to visualize the spatial relationship between the region of enhanced $N_{\mathrm{e}}$ and the moving cusp aurora. The maximum auroral intensity appears behind the moving $F$-region enhanced $N_{\mathrm{e}}$ volume created by precipitating electrons. Our method, which is based on coordinated observations from an all-sky imager and an ESR elevation scan, provides an effective approach to understanding the three-dimensional mesoscale electrodynamics of the cusp.

\section{Appendix A}

Since a tangential plane is almost equivalent to a spherical surface near the contact point, we consider the length on a spherical surface instead of a tangential plane. The intersection point of the line having a zenith angle of $\chi$ on a spherical surface at an altitude of $h$ has the following geocentric angle, $\alpha$ :

$$
\alpha=\chi-\sin ^{-1}\left(R_{\mathrm{E}} \sin \chi /\left(R_{\mathrm{E}}+h\right)\right)
$$

where $R_{\mathrm{E}}$ is the Earth radius. Evidently, for a given $\chi, \alpha$ is larger as $h$ is higher. When we consider the circumference on a spherical surface at $h=200 \mathrm{~km}$ and that at $h=300 \mathrm{~km}$ for the constant $\chi$, we can estimate the scale ratio, $S R$, as follows: 


$$
S R=\left(\left(R_{\mathrm{E}}+200\right) \sin \alpha_{200}\right) /\left(\left(R_{\mathrm{E}}+300\right) \sin \alpha_{300}\right)
$$

where $\alpha_{200}$ and $\alpha_{300}$ are the geocentric angles for $h=200 \mathrm{~km}$ and $h=300 \mathrm{~km}$, respectively. Taking $R_{\mathrm{E}}$ as $6370 \mathrm{~km}, \alpha_{200}$ and $\alpha_{300}$ are calculated from equation (A.1) for $\chi=40^{\circ}$ to be $\alpha_{200}=1.4^{\circ}$ and $\alpha_{300}=2.1^{\circ}$, respectively. Then, substituting these values into equation (A.2) yields a scale ratio of approximately 0.67 .

\section{Acknowledgements}

We would like to thank T. Aoki of University of Electro-Communications for his maintenance of the all-sky imager. We also thank F. Sigernes and M. Dyrland for their help at the University Centre in Svalbard, Longyearbyen. The assistance of Y. Sagawa, Y. Harano, and K. Sasaki with computational aspects of this research is acknowledged. EISCAT is an international association supported by research organizations in China, Finland, Germany (till end 2011), Japan, Norway, Sweden, and the United Kingdom. OMNI solar wind data were provided through the NASA CDAWeb. This work was supported by JSPS KAKENHI Grant Number 22340143.

\section{References}

Banks, P. M., Kockarts, G. J., 1973. Aeronomy, Academic, New York.

Bahcivan, H., Tsunoda, R., Nicolls, M., Heinselman, C., 2010. Initial ionospheric observations made by the new Resolute incoherent scatter radar and comparison to solar 
wind IMF, Geophys. Res. Lett., 37, L15103, doi:10.1029/2010GL043632.

Carlson, H. C., Oksavik, K., Moen, J., van Eyken, A. P., Guio, P., 2002. ESR mapping of polar-cap patches in the dark cusp, Geophys. Res. Lett., 29(10), doi:10.1029/2001GL014087.

Conrad, J. R., Schunk, R. W., 1979. Diffusion and heat flow equations with allowance for large temperature differences between interacting species, J. Geophys. Res., 84(A3), 811-822, doi:10.1029/JA084iA03p00811.

Davies, J. A., Yeoman, T. K., Rae, I. R., Milan, S. E., Lester, M., Lockwood, M., McWilliams, A., 2002. Ground-based observations of the auroral zone and polar cap ionospheric responses to dayside transient reconnection, Ann. Geophys., 20, 781-794.

Fasel, G. J., 1995. Dayside poleward moving auroral forms: A statistical study, J. Geophys. Res., 100(A7), 11891-11905, doi:10.1029/95JA00854.

Franke, R., 1982. Smooth interpolation of scattered data by local thin plate splines, Comp. and Maths. With Appls, 8, 4, pp. 273-281.

Frey, H. U., Mende, S. B., Fuselier, S. A., Immel, T. J., Østgaard, N., 2003. Proton aurora in the cusp during southward IMF, J. Geophys. Res., 108, 1277, doi:10.1029/2003JA009861, A7.

Haerendel, G., Paschmann, G., Sckopke, N., Rosenbauer, H., Hedgecock, P. C., 1978. The frontside boundary layer of the magnetosphere and the problem of reconnection, J. Geophys. Res., 83(A7), 3195-3216.

Hosokawa, K., S. Taguchi, Y. Ogawa, T. Aoki, 2013a. Periodicities of polar cap patches, J. 
Geophys. Res. Space Physics, 118, 447-453, doi:10.1029/2012JA018165.

Hosokawa, K., Taguchi, S., Ogawa, Y., Sakai, J., 2013b. Two-dimensional direct imaging of structuring of polar cap patches, J. Geophys. Res. Space Physics, 118, 6536-6543, doi:10.1002/jgra.50577.

Ishii, M., Sugiura, M., Iyemori, T., Slavin J. A., 1992. Correlation between magnetic and electric field perturbations in the field-aligned current regions deduced from DE 2 observations, J. Geophys. Res., 97(A9), 13,877-13,887, doi:10.1029/92JA00110.

Kelly, J. D., Heinselman, C. J., 2009. Initial results from Poker Flat Incoherent Scatter Radar (PFISR), J.Atmos. Solar-Terr., 71, 635, doi:10.1016/j.jastp.20 09.01.0 09.

Lockwood, M., Sandholt, P. E., Cowley, S. W. H., 1989. Dayside auroral activity and magnetic flux transfer from the solar wind, Geophys. Res. Lett., 16(1), 33-36.

Lockwood, M., Carlson Jr., H. C., Sandholt, P. E., 1993. Implications of the altitude of transient 630-nm dayside auroral emissions, J. Geophys. Res., 98(A9), 15571-15587, doi:10.1029/93JA00811.

Mende, S. B., et al., 2000. Far Ultraviolet imaging from the IMAGE spacecraft, Space Sci. Rev., 91, 243-270.

Milan, S. E., Lester, M., Cowley, S. W. H., Moen, J., Sandholt, P. E., Owen, C. J., 1999. Meridian-scanning photometer, coherent HF radar, and magnetometer observations of the cusp: a case study, Ann. Geophys., 17, 159-172.

Moen, J., Oksavik, K., Carlson, H. C., 2004a. On the relationship between ion upflow events and cusp auroral transients, Geophys. Res. Lett., 31, L11808, 
doi:10.1029/2004GL020129.

Moen, J., Lockwood, M., Oksavik, K., Carlson, H. C., Denig, W. F., van Eyken, A. P., McCrea, I. W, 2004b. The dynamics and relationships of precipitation, temperature and convection boundaries in the dayside auroral ionosphere, Ann. Geophys., 22 (6), 19731987.

Newell, P. T., Meng, C.-I., Sibeck, D. G., Lepping, R., 1989. Some low-altitude cusp dependencies on the interplanetary magnetic field, J. Geophys. Res., 94 (A7), 89218927, doi:10.1029/JA094iA07p08921.

Ogawa, Y., Fujii, R., Buchert, S. C., Nozawa, S., Ohtani, S., 2003. Simultaneous EISCAT Svalbard radar and DMSP observations of ion upflow in the dayside polar ionosphere, J. Geophys. Res., 108(A3), 1101, doi:10.1029/2002JA009590.

Ogawa, Y., Buchert, S. C., Fujii, R., Nozawa, S., van Eyken, A. P., 2009. Characteristics of ion upflow and downflow observed with the European Incoherent Scatter Svalbard radar, J. Geophys. Res., 114, A05305, doi:10.1029/2008JA013817.

Oksavik, K., Moen, J., Carlson, H. C., 2004. High-resolution observations of the small-scale flow pattern associated with a poleward moving auroral form in the cusp, Geophys. Res. Lett., 31, L11807, doi:10.1029/2004GL019838.

Rees, M. H., 1989. Physics and Chemistry of the Upper Atmosphere, Cambridge Univ. Press, Cambridge, U. K.

Russell, C. T., Elphic, R. C., 1978. Initial ISEE magnetometer results: Magnetopause observations, Space Sci. Rev., 22, 681-715, doi:10.1007/ BF00212619. 
Sandholt, P. E., Farrugia, C. J., 2003. Does the aurora provide evidence for the occurrence of antiparallel magnetopause reconnection?, J. Geophys. Res., 108(A12), 1466, doi:10.1029/2003JA010066.

Sandholt, P. E., Deehr, C. S., Egeland, A., Lybekk, B., Viereck, R., Romick, G. J., 1986. Signatures in the dayside aurora of plasma transfer from the magnetosheath, J. Geophys. Res., 91(A9), 10,063-10,079, doi:10.1029/JA091iA09p10063.

Schunk, R. W., Sojka, J. J., 1982. Ion temperature variations in the daytime high-latitude $F$ region, J. Geophys. Res., 87(A7), 5169-5183, doi:10.1029/JA087iA07p05169.

Schunk, R. W., Banks, P. M., Raitt, W. J., 1976. Effects of electric fields and other processes upon the nighttime high-latitude $F$ layer, J. Geophys. Res., 81(19), 3271-3282, doi:10.1029/JA081i019p03271.

Southwood, D. J., 1985. Theoretical aspects of ionosphere-magnetosphere-solar wind coupling, Adv. Space Res., 5(4), 7.

Southwood, D. J., 1987. The ionospheric signature of flux transfer events, J. Geophys. Res., $92,3207$.

St.-Maurice, J.-P., Hanson, W. B., 1982. Ion frictional heating at high latitudes and its possible use for an in situ determination of neutral thermospheric winds and temperatures, J. Geophys. Res., 87(A9), 7580-7602, doi:10.1029/JA087iA09p07580.

St.-Maurice, J.-P., Hanson, W. B., 1984. A statistical study of F region ion temperatures at high latitudes based on Atmosphere Explorer C data, J. Geophys. Res., 89(A2), 987-996, doi:10.1029/JA089iA02p00987. 
Sugiura, M., Maynard, N. C., Farthing, W. H., Heppner, J. P., Ledley, B. G., Cahill Jr., L. J., 1982. Initial results on the correlation between the magnetic and electric fields observed from the DE-2 satellite in the field-aligned current regions, Geophys. Res. Letts., 9: 985-988, doi: 10.1029/GL009i009p00985.

Taguchi, S., Sugiura, M., Winningham, J. D., Slavin, J. A., 1993. Characterization of the IMF $B_{\mathrm{Y}}$-dependent field-aligned currents in the cleft region based on DE 2 observations, J. Geophys. Res., 98, 1393-1407.

Taguchi, S., Suzuki, S., Hosokawa, K., Ogawa, Y., Yukimatu, A. S., Sato, N., Collier, M. R., T. E. Moore, 2009. Moving mesoscale plasma precipitation in the cusp, J. Geophys. Res., 114, A06211, doi:10.1029/2009JA014128.

Taguchi, S., Hosokawa, K., Suzuki, S., Tawara, A., Frey, H. U., Matzka, J., Yukimatu, A. S., Sato, N., 2010. Plasma flow during the brightening of proton aurora in the cusp, J. Geophys. Res., 115, A10308, doi:10.1029/2010JA015535.

Taguchi, S., Hosokawa, K., Ogawa, Y., Aoki, T., Taguchi, M., 2012. Double bursts inside a poleward-moving auroral form in the cusp, J. Geophys. Res., 117, A12301, doi:10.1029/2012JA018150.

Wahlund, J.-E., Opgenoorth, H. J., Häggström, I., Winser, K. J., Jones, G. O. L., 1992. EISCAT observations of topside ionospheric ion outflows during auroral activity: Revisited, J. Geophys. Res., 97(A3), 3019-3037, doi:10.1029/91JA02438. 


\section{Figure captions}

Fig. 1. (a) Observation of a moving cusp aurora (indicated by the pink arrow) by an all-sky imager at 0936:02 UT on 13 January 2013. The 630.0-nm all-sky image is projected onto an Earth-centered sphere at a height of $300 \mathrm{~km}$, with a background of a geomagnetic coordinate system. The star symbol indicates the location of Longyearbyen, Svalbard. The positive $X$ direction is toward geographically southeast, and the positive $Y$ direction is toward geographically northeast. The dotted rectangle, which includes the auroral form, is a region made from sides parallel to the $X$-axis and the $Y$-axis.

Fig. 2. Example of the spatial relationships between the ESR's field of view and the auroral form (main panel) and schematic illustration of the coordinate system used in this study (inset). The horizontal axis of the main panel ( $X$-axis, right is positive) is geographically southeast. The $Y$-axis is toward geographically northeast. This $X$ - $Y$ plane is a tangential plane of the sphere at an altitude of $300 \mathrm{~km}$. The gray line at $Y=0$ represents the range over which the ESR beam intersects this plane. Inset shows the configuration in the $Y=0$ plane. The black dot in the inset indicates the location of ESR. Two ESR beams having elevation angles of $30^{\circ}$ and $60^{\circ}$ are shown. $X=0$ represents the origin of the coordinate system.

Fig. 3. Solar wind data during $0700-1100$ UT on 13 January 2013. Seven panels show the 5 min OMNI data, plotting GSM $B_{\mathrm{X}}, B_{\mathrm{Y}}$, and $B_{\mathrm{Z}}$ components of the interplanetary magnetic 
field (IMF), the IMF clock angle, the solar wind proton density, flow speed, and dynamic pressure. The dotted line indicates the time at which the aurora image shown in Figures 1 and 2 was captured, specifically 0936:02 UT.

Fig. 4. Images of the moving cusp aurora taken at (a) 0935:22, (b) 0936:08, and (c) 0936:49 UT. Each image has the same format as Figure 2, except for having a black dot inside the image. This dot indicates the location of the maximum intensity in each auroral form. The arrows in (b) indicate the range over which the auroral form is located relatively deep into the positive $Y$ region, between $X=-80 \mathrm{~km}$ and $X=-160 \mathrm{~km}$.

Fig. 5. Positions of the maximum intensity of the auroral form with time, throughout the lifetime of the moving cusp aurora. The definition of the $X$ - and $Y$-axes is the same as that in Figures 2 and 4 . The positive $X$ direction is toward geographically southeast, and the positive $Y$ direction is toward geographically northeast. The red line is an ordinary least squares linear regression fit for points obtained from the images taken during 0935:02-0936:49 UT.

Fig. 6. The 12.8-s integrated ESR data (a to d) and the elevation angle of the ESR beam for 0932:00-0940:00 UT (e). Boxes labeled 1 to 7 in (a) and (c) represent times when observations were made at an elevation angle of $40^{\circ}-50^{\circ}$. These angle ranges are also shown as $A$ to $D$ in (e). The black triangles immediately above (a) represent the period when the aurora of interest was observed. The red triangle indicates a time that is $110 \mathrm{~s}$ earlier than the 
time shown by the left black triangle.

Fig. 7. (a) ESR electron density, (b) ion temperature, and (c) elevation angle of the ESR beam for the interval of 0933:00 - 0937:00 UT. Formats of (a), (b), and (c) are the same as those of Figure $6 a, 6 c$, and $6 \mathrm{e}$, respectively. The boxes labeled 1 to 7 also show the same 12.8-s intervals as those shown in Figure 6.

Fig. 8. (a) Variations in electron densities (blue) and ion temperatures (red) at altitudes of 300 $\mathrm{km}$ and $260 \mathrm{~km}$ for the intervals labeled 0 to 7. (b) Variations in auroral intensity as it passed through three points $(X, Y, Z)=(-80,0,300),(-120,0,300)$, and $(-160,0,300) \mathrm{km}$. Horizontal axis is the time from 0932:32 UT. The error in (a) represents one standard deviation. The upward blue arrow in (a) indicates the time when the electron density reaches its maximum (time 6). The vertical line in (b) shows the time when the auroral intensity reaches its maximum.

Fig. 9. Positions of the ESR beam at $Z=300 \mathrm{~km}$, obtained from equation (2). Each black dot indicates the position with 3.2-s time steps, starting at 0933:20 UT. The gray arrows labeled 1 to 7 indicate 12.8-s (4 times 3.2-s) intervals, which are also shown in Figures 6 and 7. The dotted lines labeled a1 and a 2 represent 12.8 -s intervals just before the observation at times 1 and 5, respectively. 
Fig. 10. Three-dimensional images of (a) enhanced electron densities and (b) elevated ion temperature as viewed from the negative $Y$ side. White downward arrows represent the direction of the Earth's magnetic field. These arrows are shown in the $Z$ range between 250 $\mathrm{km}$ and $300 \mathrm{~km}$ in (a) and between $200 \mathrm{~km}$ and $250 \mathrm{~km}$ in (b). In (b) $A, B, C$, and $D$ represent four parts of the elevated ion temperature region.

Fig. 11. $Y$ - $Z$ profiles of (a) enhanced electron densities and (b) elevated ion temperature. The white dot in each Figure represents the origin defined in Figure 2. In (b) Region $B$ on the more (or less) positive $Y$ side of $Y=100 \mathrm{~km}$ is referred to as Region $B_{1}$ (or Region $B_{2}$ ).

Fig. 12. Difference between $T_{\mathrm{i}}$ and $T_{\mathrm{e}}$ within the heated volume as a function of altitude.

Fig. 13. Distribution of the calculated flow vector and ion temperature, showing the interpretation of the relative position of the lower-altitude elevated $T_{\mathrm{i}}$ volume to the enhanced $N_{\mathrm{e}}$ volume. The vertical $y$-axis represents the direction of the background flow, which is almost east-northeastward (ENE). This $y$-axis is different from the $Y$-axis in Figures 1 and 2. The long black arrow indicates the direction of the ESR's field of view. Four contours show the ion temperatures of $2000 \mathrm{~K}, 2500 \mathrm{~K}, 3000 \mathrm{~K}$, and $4000 \mathrm{~K}$. The hatched semicircle represents a region of field-aligned current flowing out of the ionosphere, corresponding to the enhanced $N_{\mathrm{e}}$ region. The other semicircle is a region of field-aligned current flowing into the ionosphere. 
Fig. 14. Positions of the auroral form of interest during 0935:02 - 0936:49 UT, estimated from the most distant point of the auroral emission of more than $2.5 \mathrm{kR}$, and the comparison to the result obtained in Figure 5. The blue line is an ordinary least squares linear regression fit for the 10 positions, and the red line is from the result obtained in Figure 5. The magnitude of the estimated average velocity $\left(V_{\mathrm{AVE}}\right)$, the unit vector $(\boldsymbol{e})$ of the velocity direction, and the velocity vector $\left(\boldsymbol{V}_{\mathrm{AVE}}\right)$ are shown. 


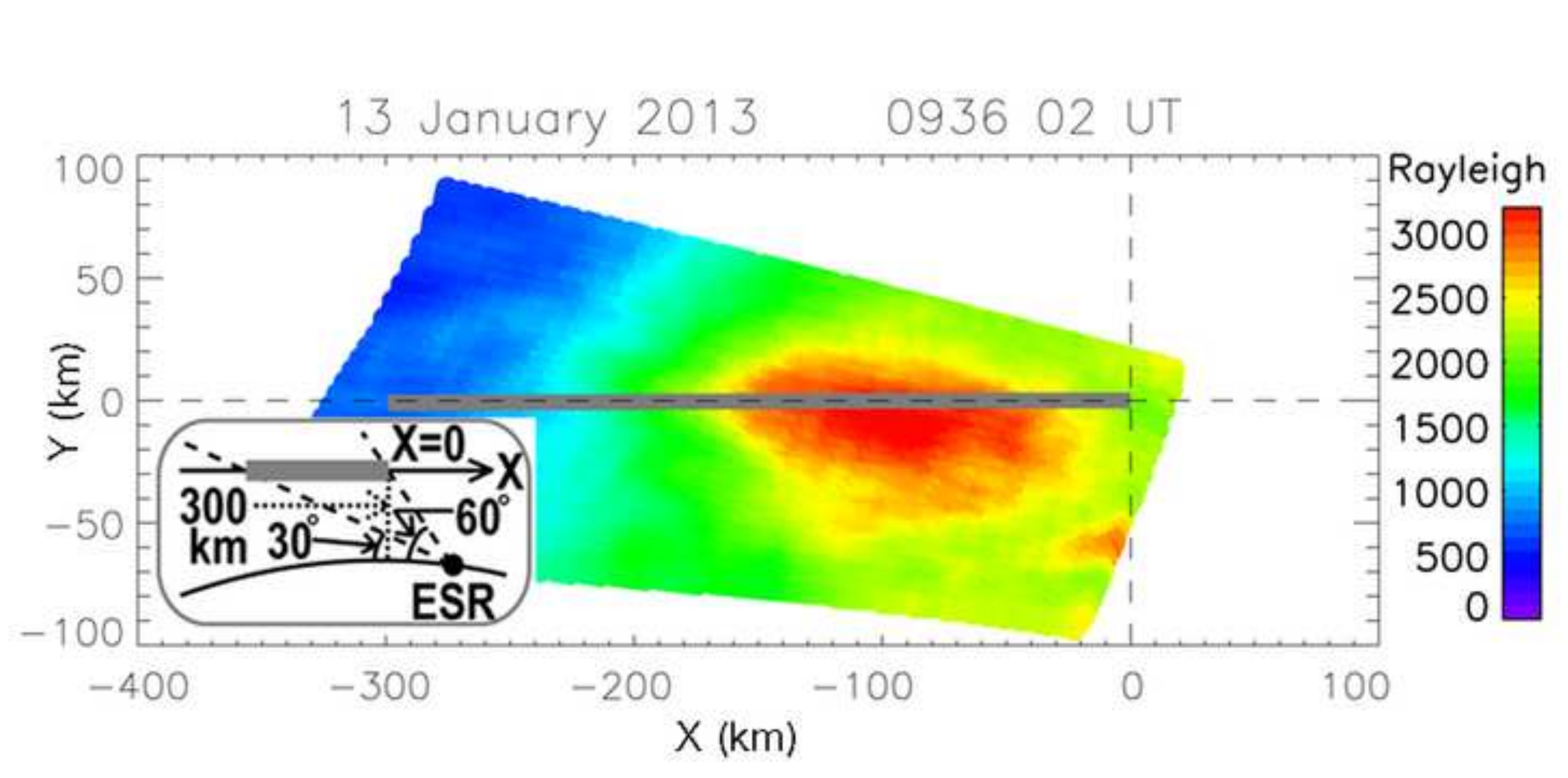


Solar Wind ( 5 min OMNI) 13 January 2013

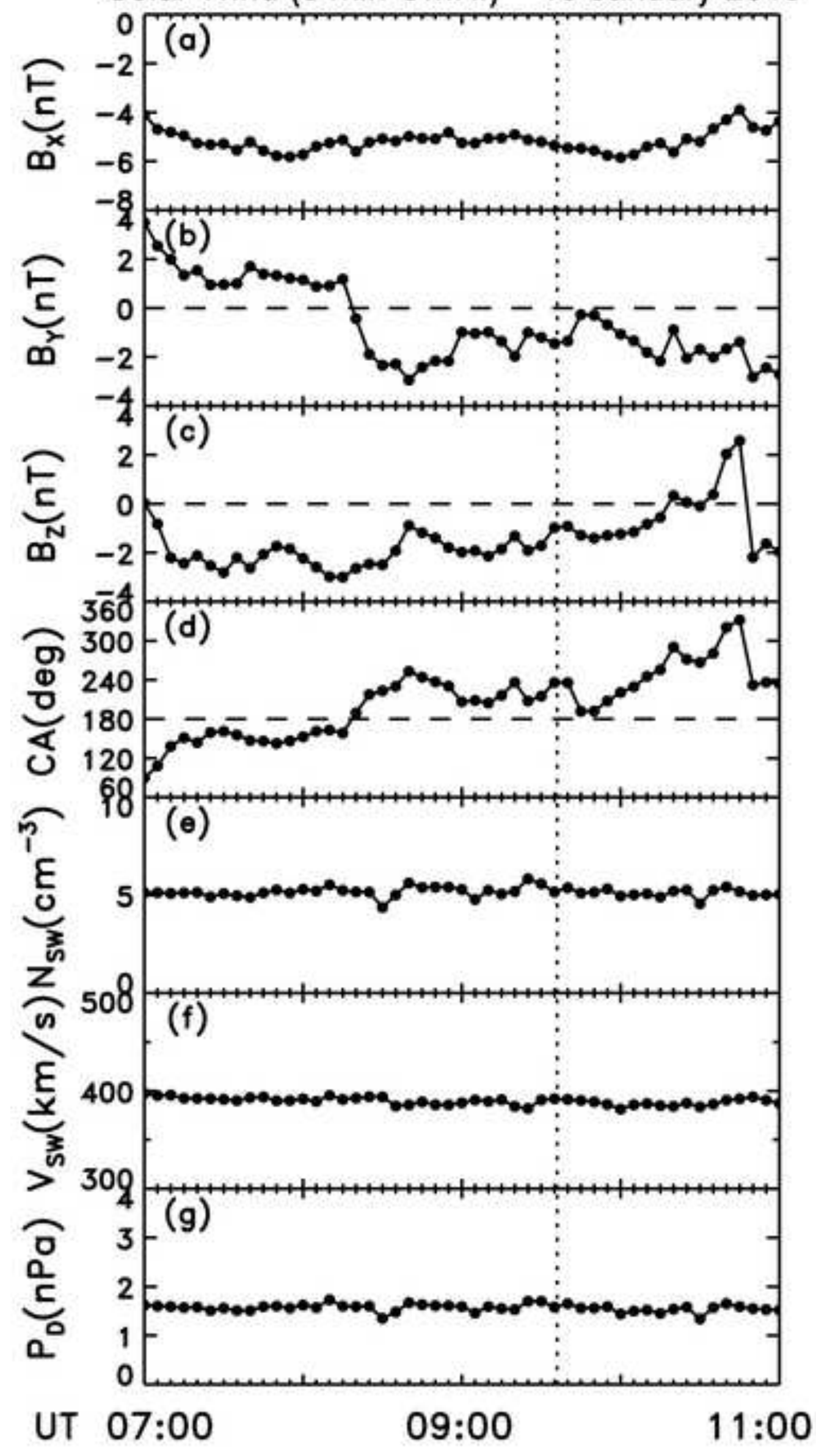




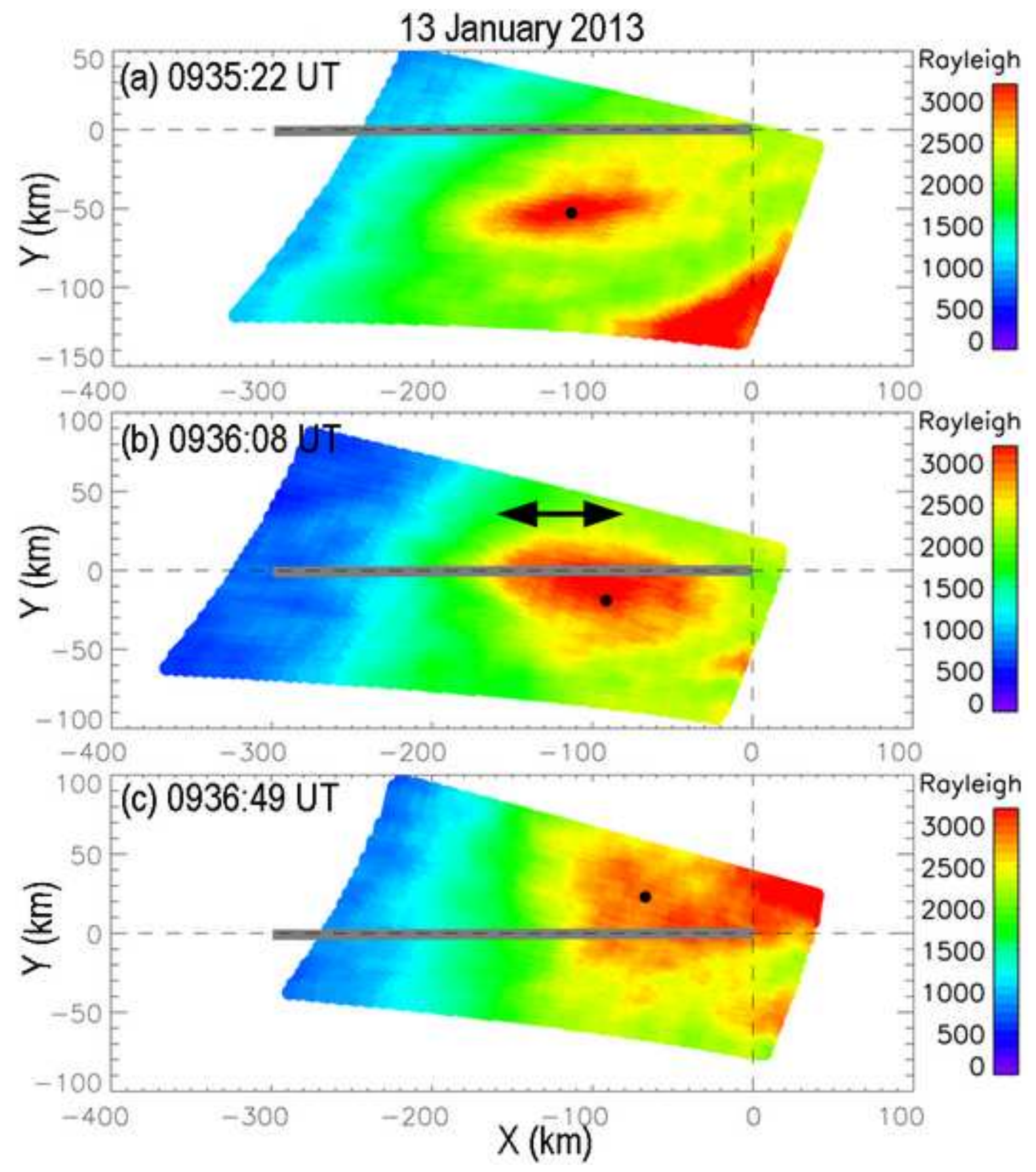




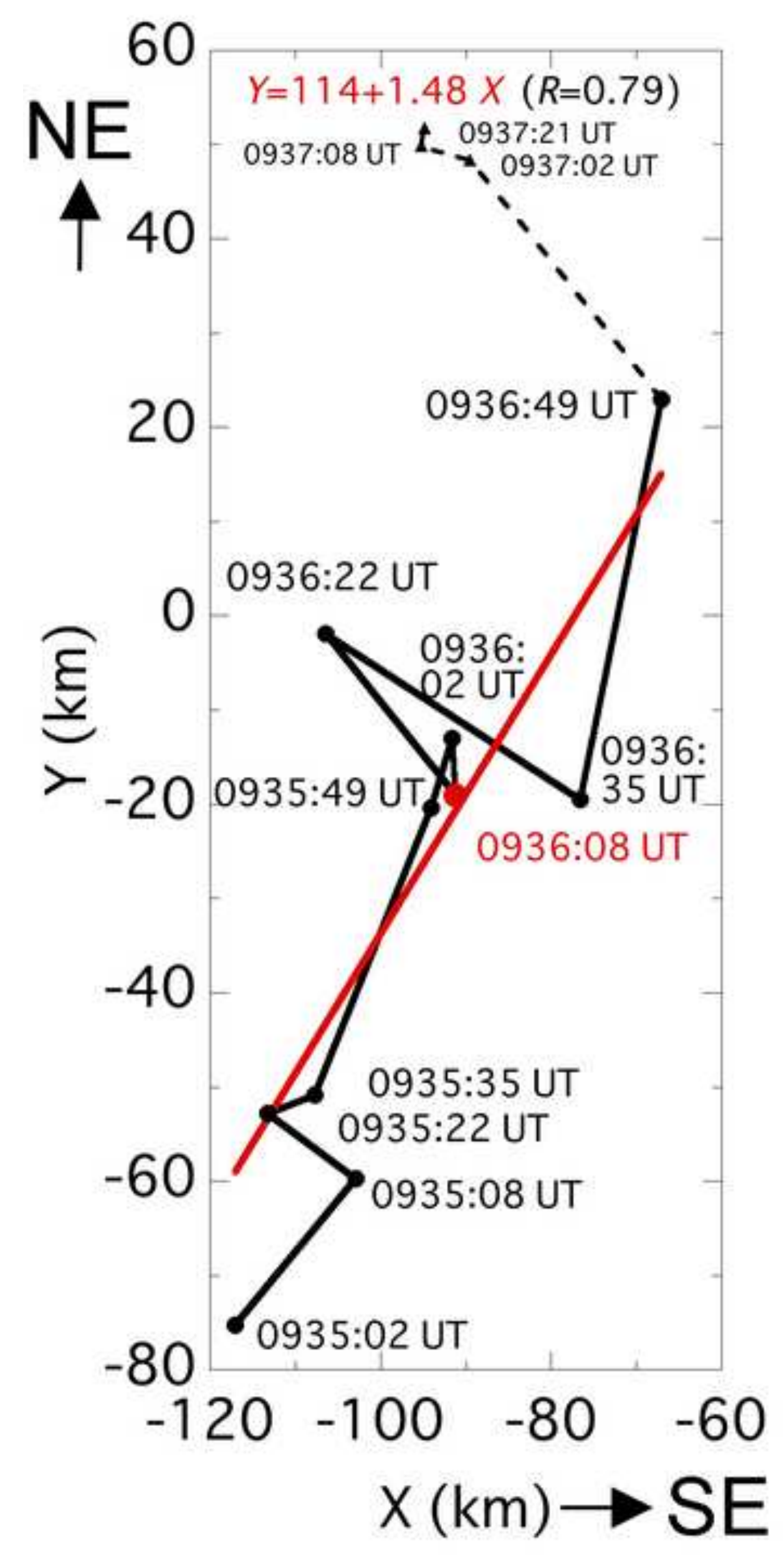




\section{EISCAT SVALBARD RADAR}

\section{SP, 32ma, folke, 13 January 2013}
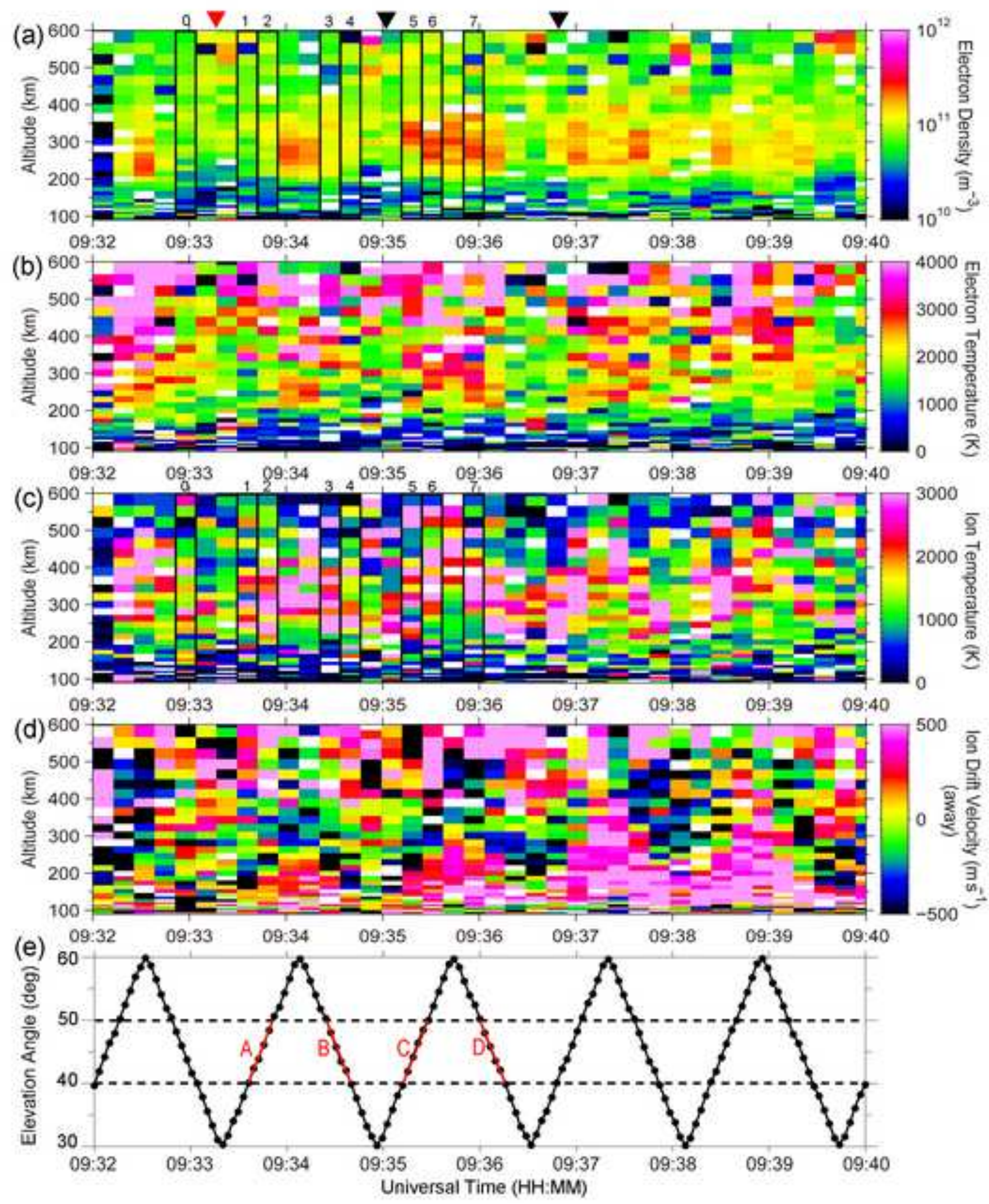


\section{EISCAT SVALBARD RADAR}
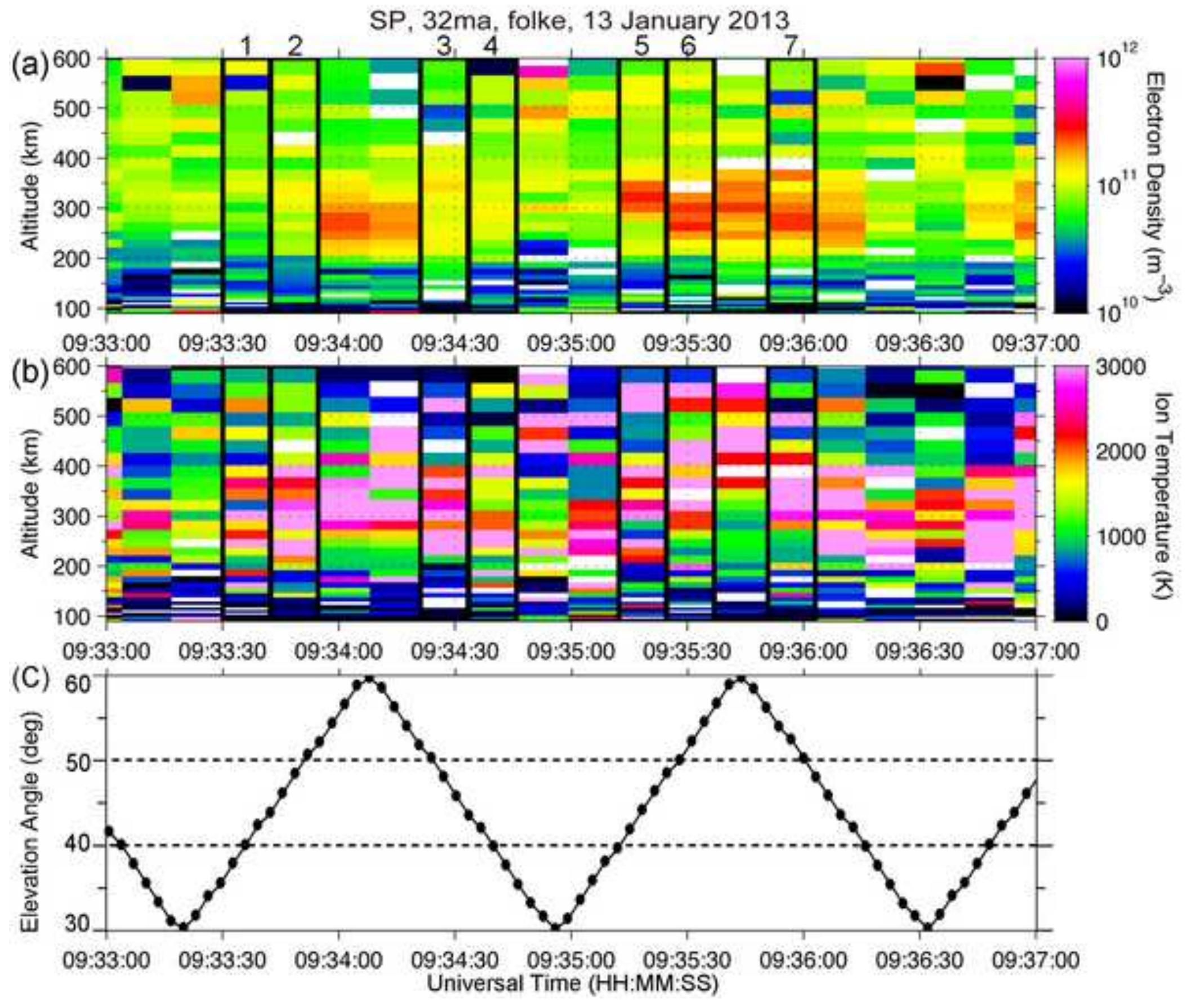
ESR and All-sky Imager

(a) 6000 0932:32 UT 13 January 2013

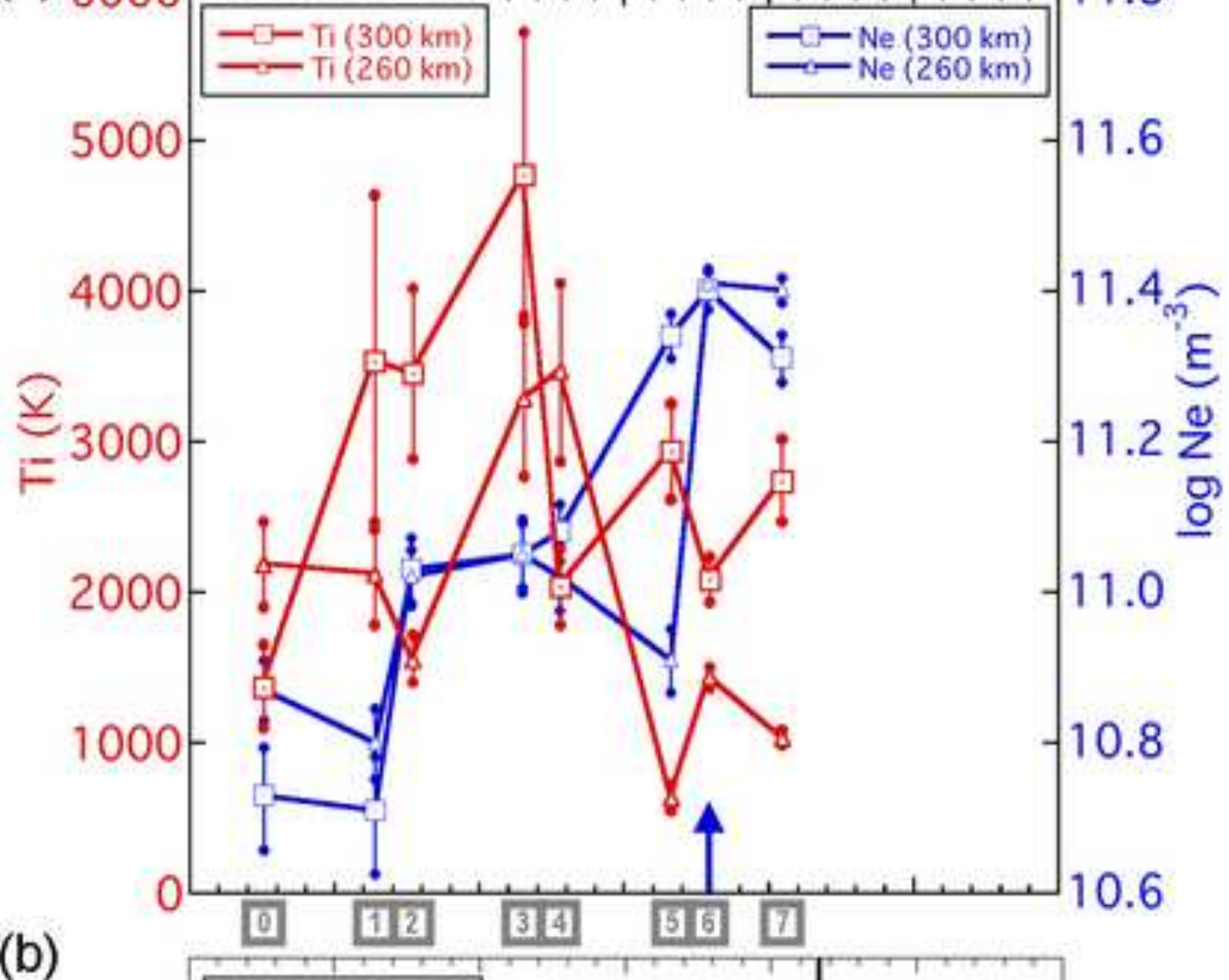

(b)
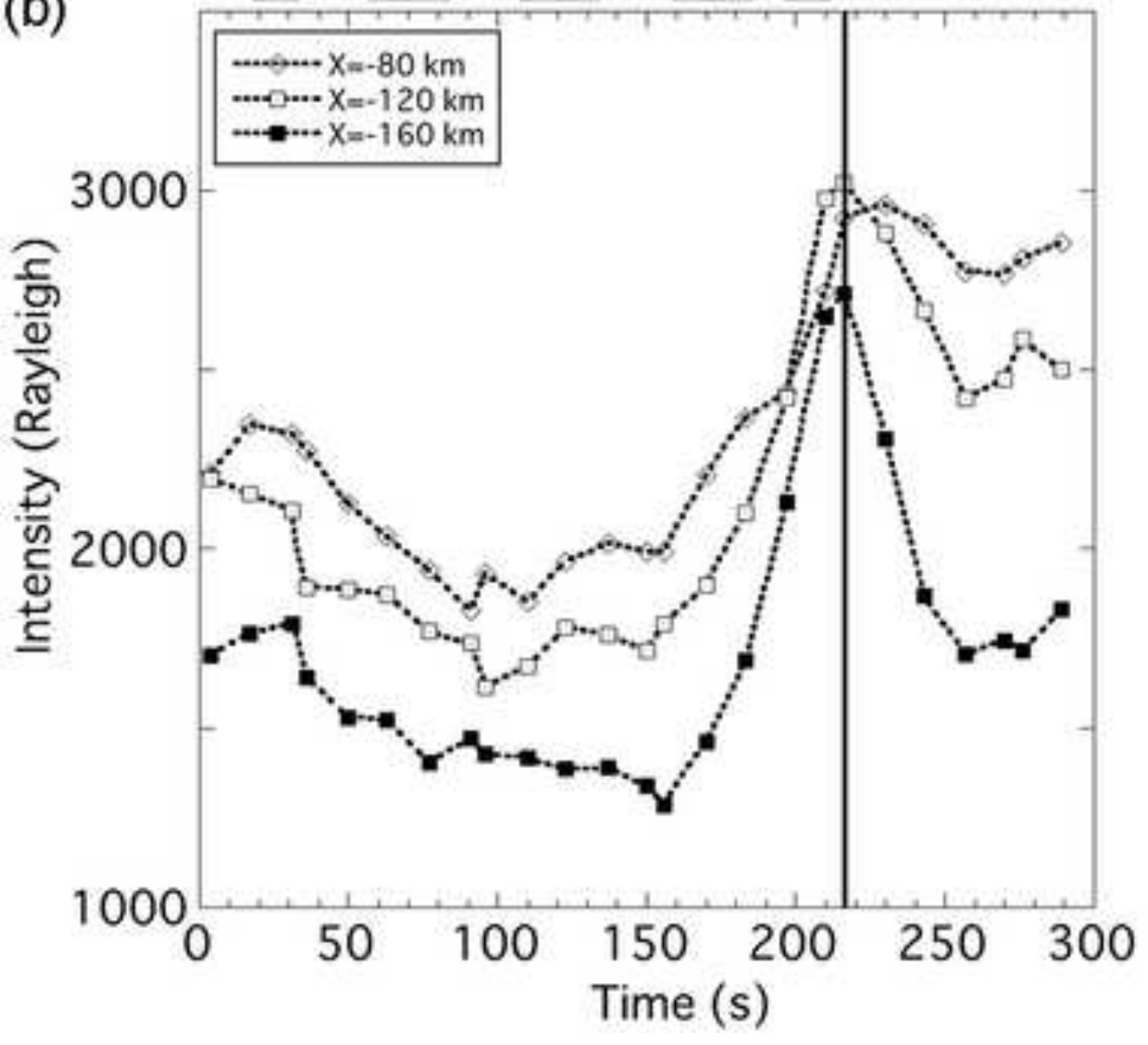

$-$ 


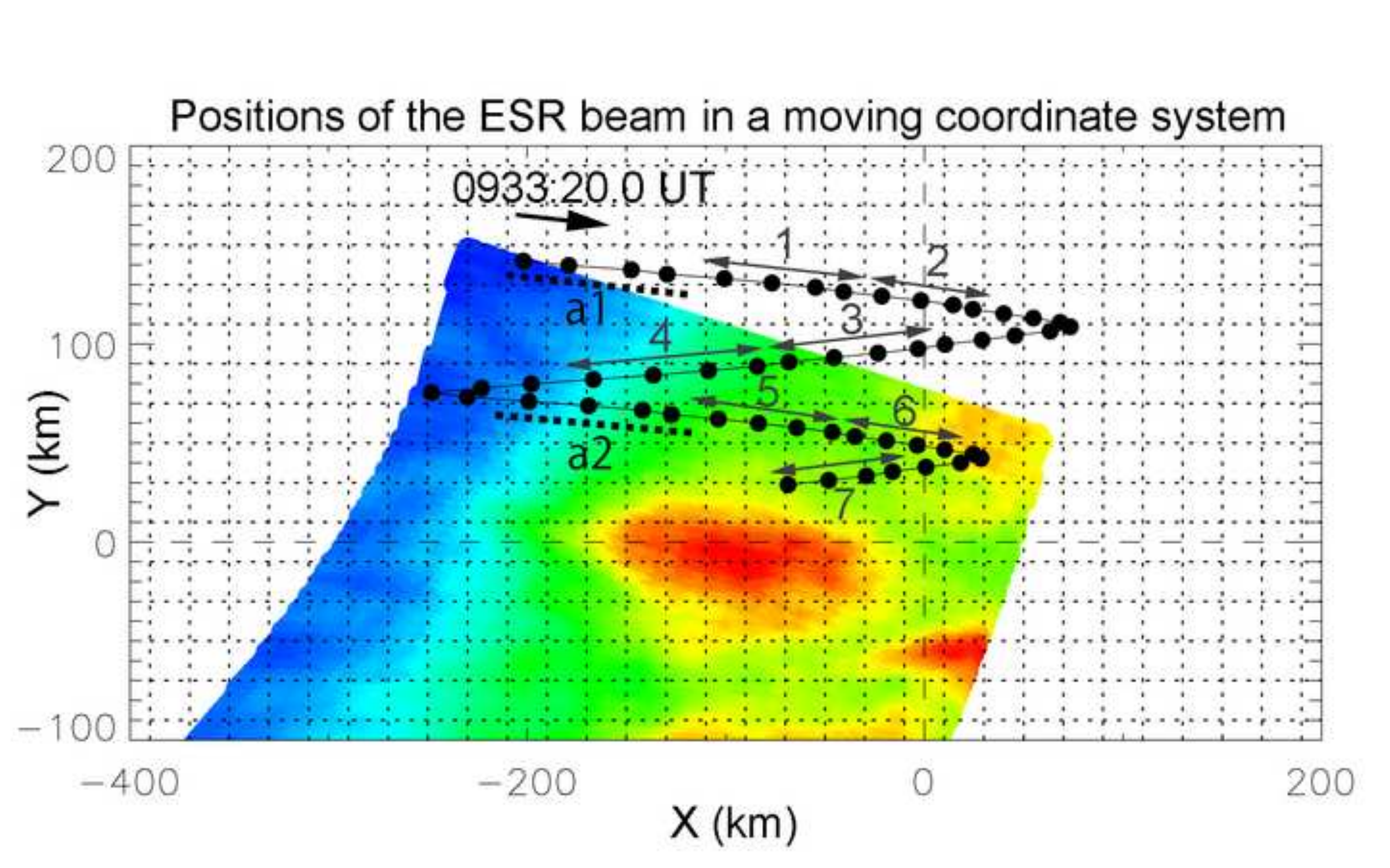

\section{Positions of the ESR beam in a moving coordinate system}

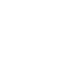

-

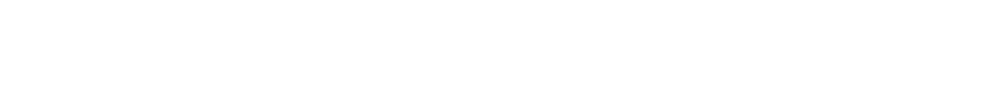

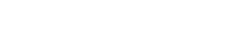

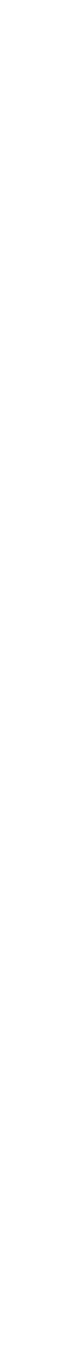


(a)

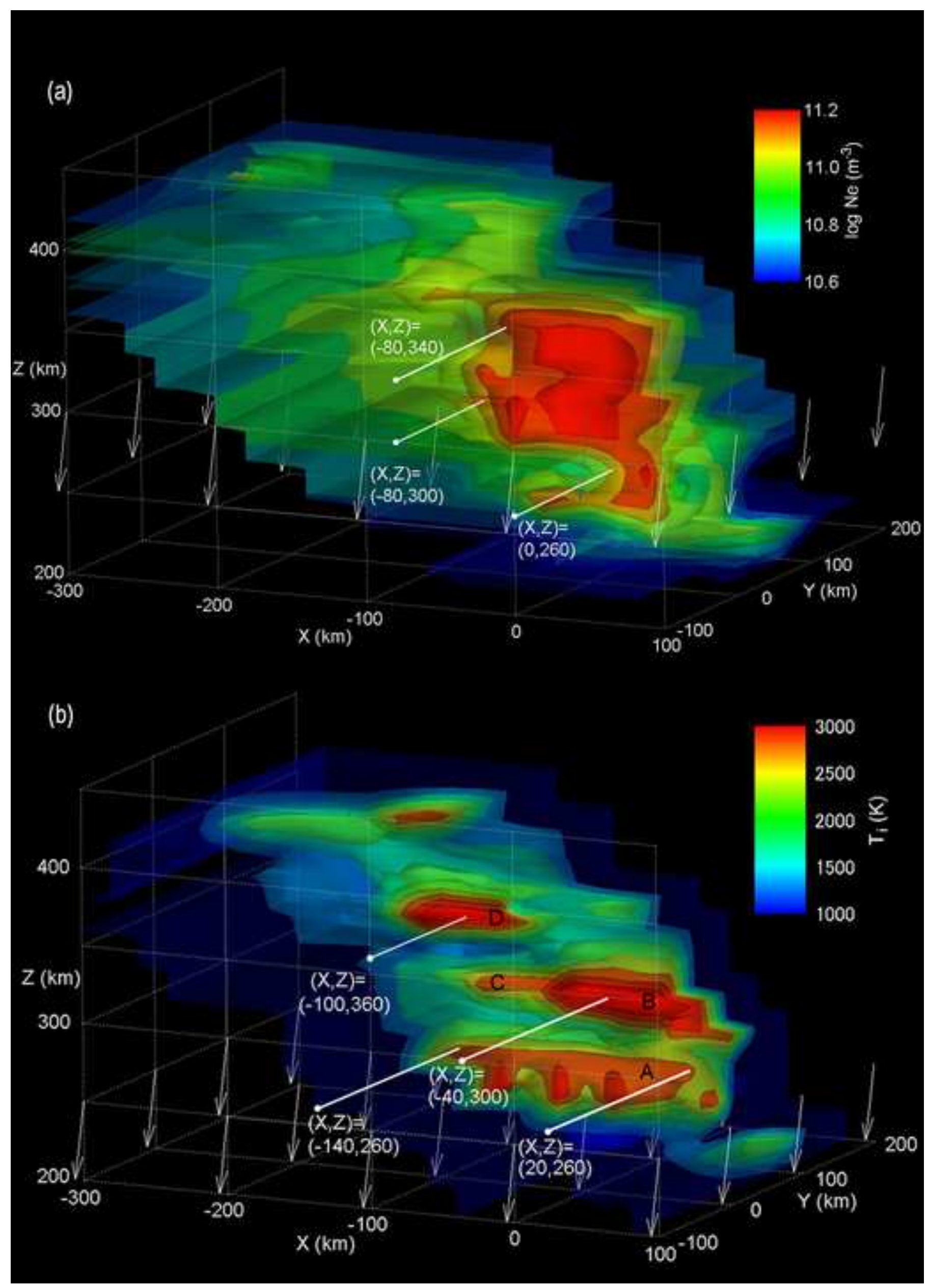




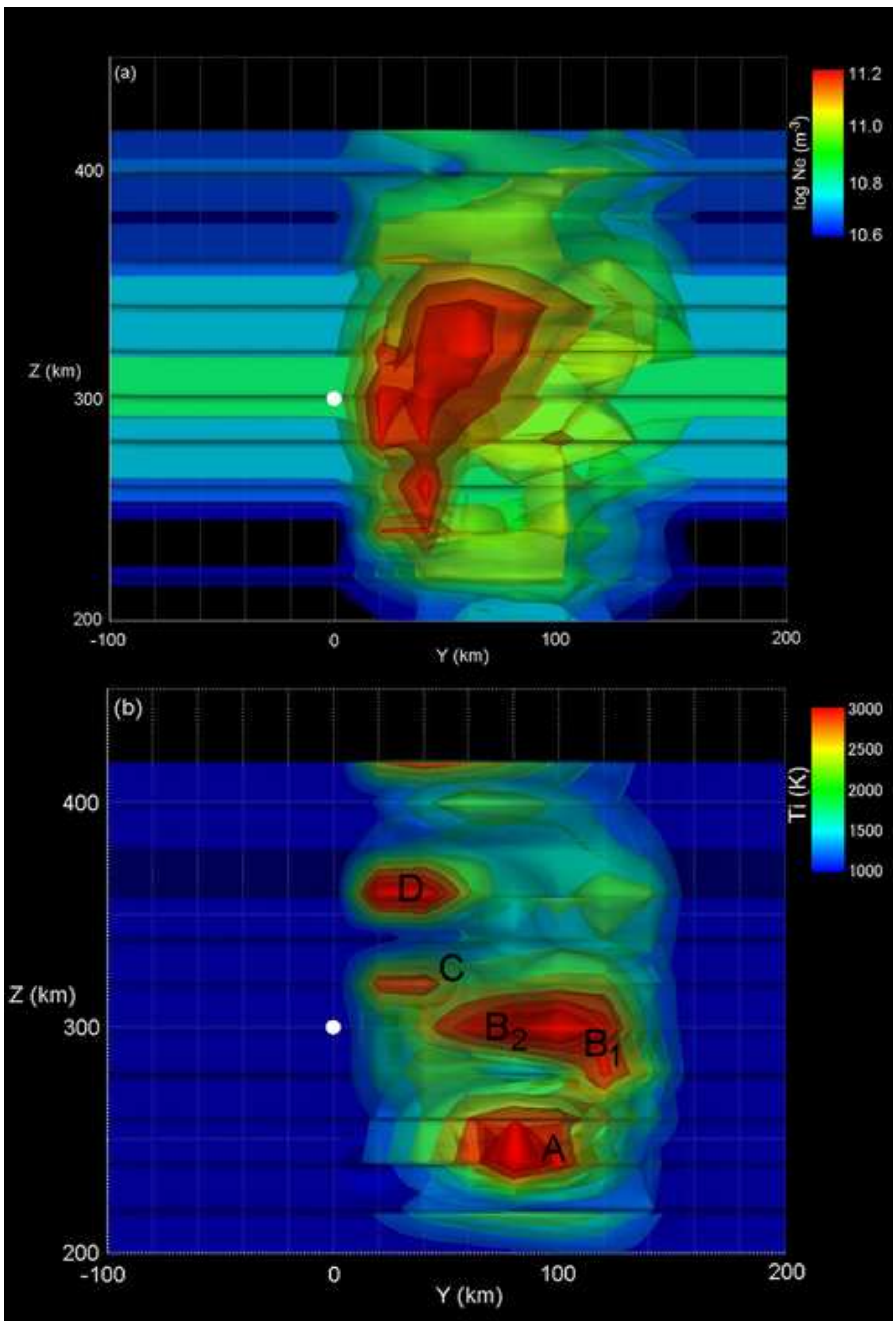




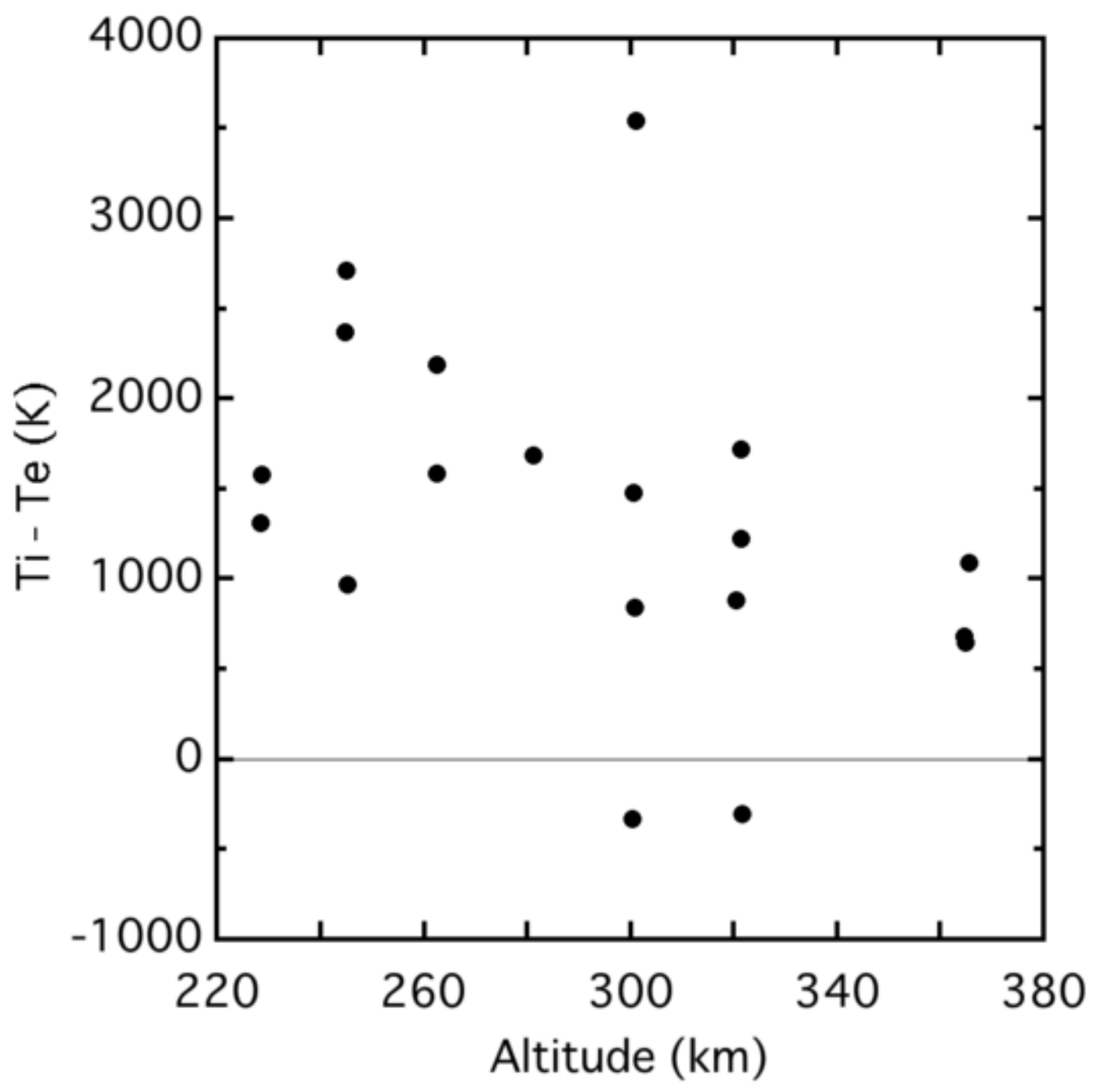




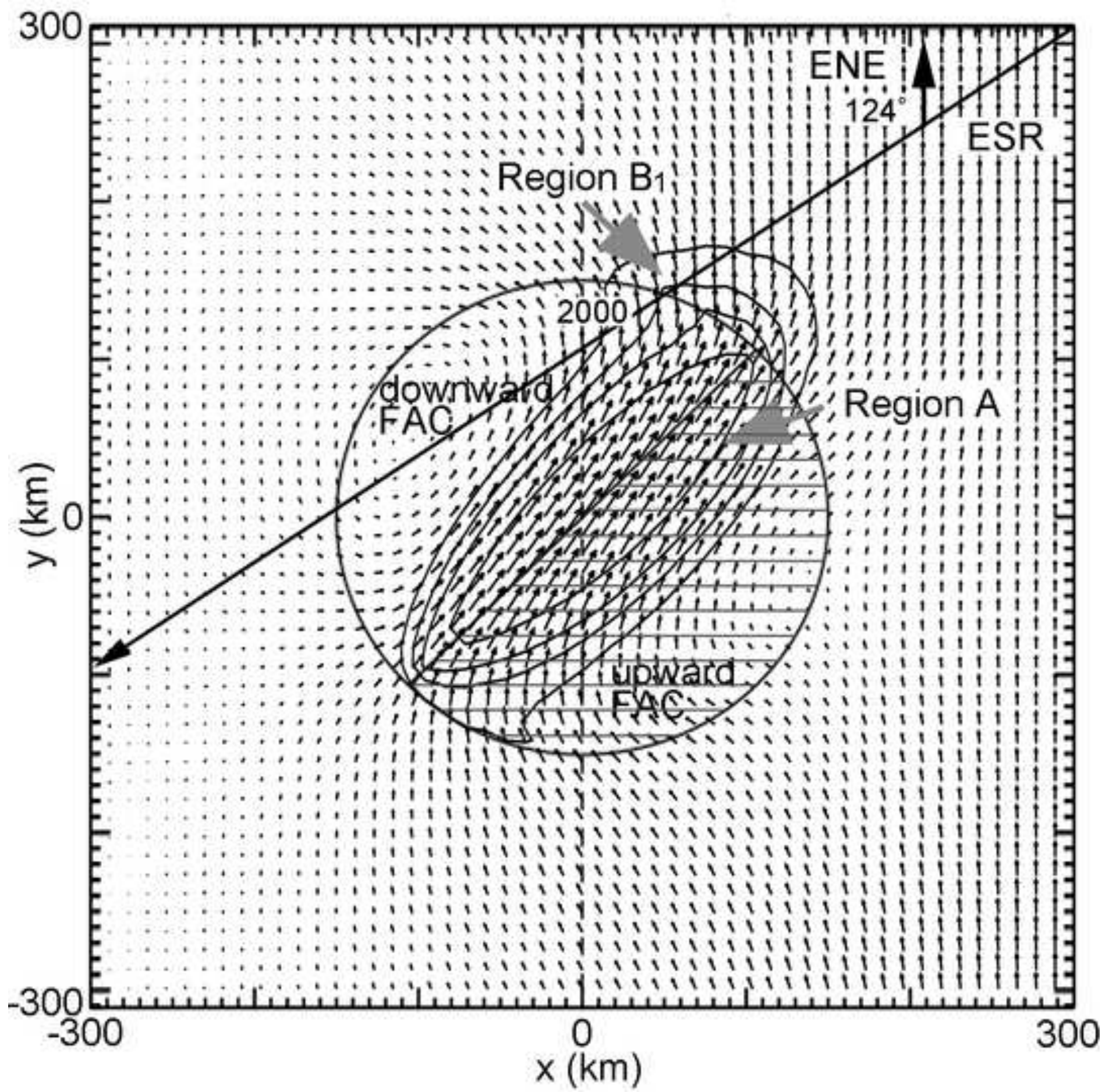




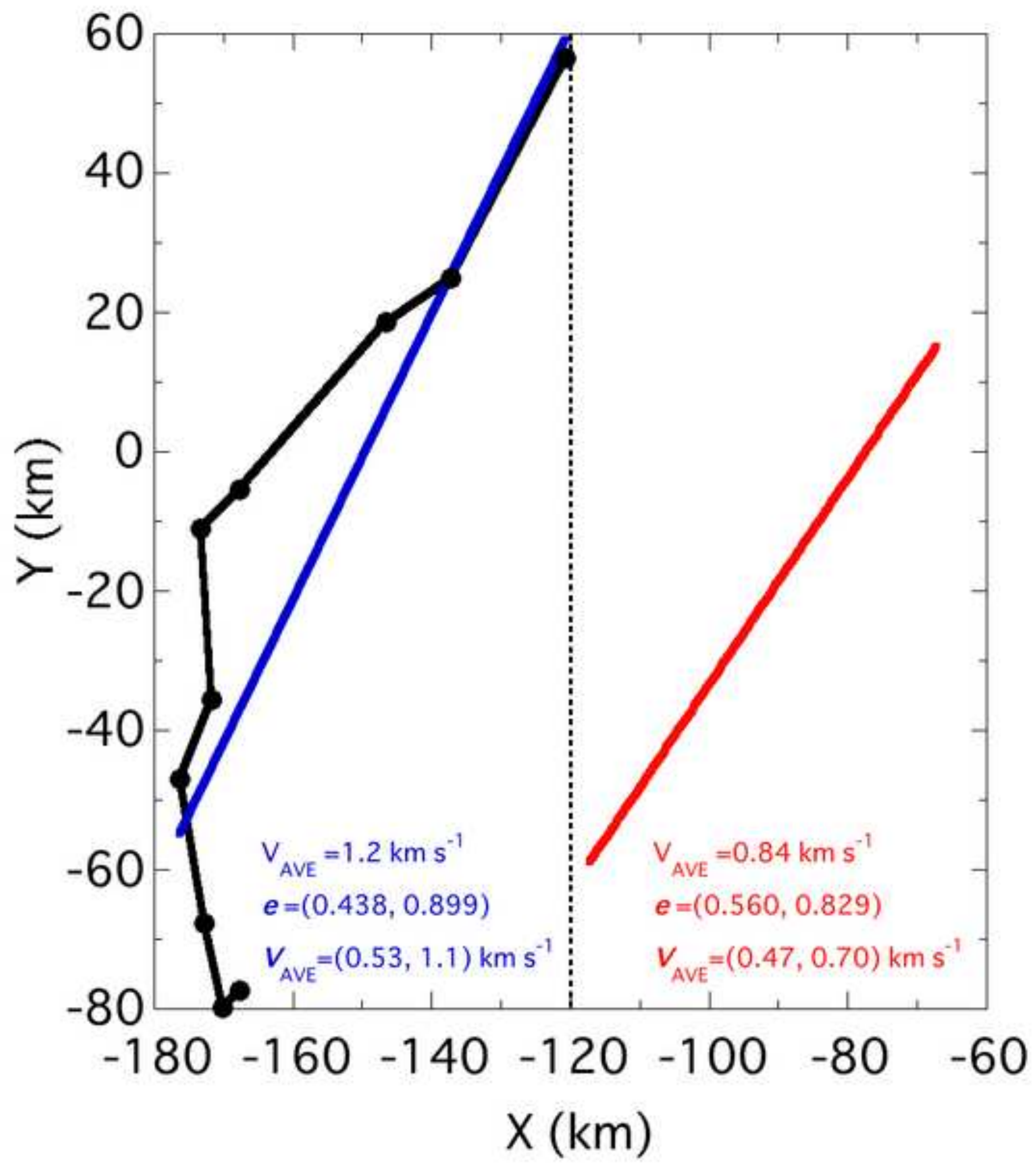

$$
\begin{gathered}
-180-160-140-120-100-80-60 \\
X(k m)
\end{gathered}
$$

